\title{
Welfare and sustainability effects of dietary recommendations
}

\author{
Xavier Irz, ${ }^{\text {P Pascal Leroy, }}{ }^{\mathrm{b}}$ Vincent Réquillart, ${ }^{\mathrm{c}}$ Louis-Georges Soler ${ }^{\mathrm{b}}$
}

aLUKE Natural Resources Institute Finland, Latokartanonkaari 9, 00790 Helsinki, Finland

bINRA Aliss, 65 Boulevard de Brandebourg, 94205 Ivry-sur-Seine, France

'Toulouse School of Economics, Université Toulouse Capitole (INRA), Manufacture des Tabacs, 21 Allée de Brienne, 31000 Toulouse, France

\begin{abstract}
The paper develops a framework combining a model of rational behaviour under dietary constraints, an epidemiological model of diet-related mortality, and a life-cycle-analysis model of environmental impact, which permits the ex-ante assessment of dietary recommendations in multiple sustainability dimensions (i.e., taste cost, welfare effect, deaths avoided, reductions in greenhouse gas emissions and acidification). It is applied to compare in a French context the relative effects and efficiency of six popular sustainable diet recommendations. The results confirm the synergies between the health and environmental dimensions: healthyeating recommendations usually have a positive effect on the environment, although some exceptions exist. Most of the sustainable diet recommendations appear highly cost-effective, but those most commonly promoted on health grounds (e.g., targeting consumption of salt, fruits and vegetables and saturated fat) rank highest in terms of overall efficiency. Moreover, the valuation of benefits indicates that in most cases health benefits are significantly larger than environmental benefits. Overall, the analysis reveals some under-investment in the promotion of sustainable diet recommendations in France. The general lack of enthusiasm in policy circles for informational measures promoting behavioural change may reflect unrealistic expectations about the speed and magnitude of dietary change rather than an objective assessment of the efficiency of those measures.
\end{abstract}

Keywords: food choice; rationing; norms; healthy; nutrition; cost-benefit

Classification: D1; D6; I1; Q5

\section{Acknowledgments:}

The authors want to thank the Editor and the two reviewers for their helpful comments and suggestions. Financial support from the ANR-French National Research Agency, project ANR-011-ALID-002-02 OCAD, and from the ERANET-SUSFOOD call (Project SUSDIET) is gratefully acknowledged. 


\section{Welfare and sustainability effects of dietary recommendations}

\section{Introduction}

Food consumption patterns observed in developed countries raise two main types of concerns. First, it is widely recognized that the food sector contributes significantly to climate change through high greenhouse gas emissions (GHGEs): from 15 to $30 \%$ of total GHGEs are induced by food production, distribution and consumption (Esnouf et al., 2013). For this reason, changes in consumers' diets are often considered as an important driver of climate change mitigation (Hoolohan et al., 2013; Carlson-Kanyama and Gonzalez, 2009; Tukker et al., 2011) and many reports suggest promoting new consumption patterns based on the reduction of meat and dairy consumption and the substitution of meat products by plant-based products within the diets of high-income country consumers (FAO, 2010; Stehfest et al., 2009; Berners-Lee et al., 2012; Friel et al., 2009).

Second, unhealthy diets, in association with physical inactivity, are risks factors strongly related to various chronic diseases, including obesity, strokes, diabetes, and some types of cancers (World Health Organization, 2003). This statement has led many public health agencies to set up prevention policies based on healthy-eating messages and information campaigns (Mazzocchi and Traill, 2011). Most frequent messages promoted by health agencies encourage individuals to adopt healthier diets and consume more fruit and vegetables (F\&V) (Cappacci and Mazzocchi, 2011) and less salt (Shankar et al., 2013). Starchy foods products are other food groups whose consumption is often promoted by public health experts (Mancino et al., 2008), whereas some of them have recommended a decrease in consumption of soft drinks (Jou and Techakehakij, 2012).

As noted by McDiarmid et al. (2012), health and environmental issues need to be tackled together to ensure consistent dietary advice for consumers. Despite the fact that the convergence between health and environmental challenges is not systemically guaranteed (McDiarmid et al., 2012; Vieux et al., 2012; Masset et al., 2014), it is now widely accepted that the reduction of meat consumption and the shift toward plant-based diets would have a favorable effect on both environment and health (Pimentel and Pimentel, 2003; Soret et al., 2014; Berners-Lee et al., 2012; McEvoy et al., 2012; Aston et al., 2012; Scarboroug et al., 2014).

Indeed, on the one hand, red meat is suspected to have a causal influence on colorectal cancer and other forms of cancers and may be associated with cardiovascular diseases because of its high cholesterol and saturated fat acids (SFA) contents (McMichael et al., 2007). On the other hand, plant-based products have much lower impacts on GHGEs than animal-based products (Masset et al., 2014).

Whether for health or environmental benefits, consumers are then more and more urged to make food choices while complying with a whole range of dietary recommendations which target health and environmental benefits. Education and information campaigns and food labeling are implemented in order to induce these dietary changes. However, a lot of research shows that the adoption of new diets by consumers are difficult for many, with campaigns raising, for instance, awareness of nutritional issues without having a large impact on behaviours (Pérez-Cueto et al., 2013). 
If several reasons can be proposed to explain the difficulties in changing behaviours, one is related to the "taste cost" of change, that is, the utility loss induced by a dietary change that brings a new balance between long-term health or environmental goals and short-term pleasure and hedonistic rewards (Réquillart et Soler, 2014). In other words, the difficulties in complying with new food-based guidelines are likely due to the lack of compatibility of consumers' preferences with the diets that they would have to adopt in order to comply with these guidelines.

An important issue is then to determine sustainable diets complying with health and environmental recommendations and compatible, as much as possible, with consumer preferences. In other words, the challenge is to identify dietary recommendations with the potential to improve health and environment but generating the smallest "taste costs" for the consumers.

A first group of methods to address this issue builds on linear programming (LP) models which are used to estimate least-cost diets complying with a list of dietary requirements (Henson, 1991; Conforti and d'Amicis, 2000). Such LP models have been recently used by nutritionists to determine optimal diets complying with nutritional or environmental recommendations (Darmon et al., 2006; Maillot et al., 2010; Macdiarmid et al., 2012; Darmon et al., 2002, 2003; Srinivasan et al., 2006; Shankar et al., 2008; Arnoult et al., 2010). These methods suffer from important shortcomings because the objective functions and the substitution possibilities among goods are always arbitrarily restricted, and not based on real consumers' preferences. Therefore they cannot really take into account the consumers' taste costs and then be used to infer how nutritional and environmental dietary norms might influence real-world consumers.

A second type of approach with a stronger theoretical basis uses empirically-estimated demand systems (see Thow et al. 2010, Etilé, 2011, and Eyles et al., 2012 for recent reviews). These studies typically estimate price elasticities from demand curves, which are conceptually derived from constrained utility maximization, given prices and a budget constraint. This kind of research has been based on complete food demand systems (Smed et al., 2007, Allais et al. 2010; Briggs et al., 2013; Caillavet et al., 2014), which allows consideration of a large set of interdependent demand relationships. Such methods can support the simulation of impacts of price policies, taxes or subsidies, on food consumption and nutrient intakes. However, compliance with food-based or nutrientbased recommendations can only be assessed ex-post rather than introduced as constraints in order to determine the price modifications needed to comply with these constraints.

To overcome these limits, Irz et al. (2015) have developed a new analytical framework which builds on the microeconomic theory of the consumer under rationing, with the goal of identifying diets compatible with both dietary recommendations and consumer preferences. This framework is built to estimate the substitutions, and overall changes in diet, that would take place if consumers complied with these recommendations. Such a framework is used to assess the difficulty of achieving a given norm by identifying the magnitude and nature of the required substitutions in consumption. It also provides the basis for measuring the "taste cost" of complying with a particular nutritional dietary norm, which can then be used in conventional cost-benefit analysis. Compared to the demand system analyses used to assess the effect of price variations on consumption and nutrient intakes (and then finally, on compliance with nutritional or environmental recommendations), this method considers the dual problem which consists of determining the price system and the compensation value (i.e. the taste cost) such that a dietary recommendation can be adopted without loss of utility. 
In the present paper, we use this theoretical framework to empirically estimate the health, environmental and welfare impacts of the adoption of various dietary guidelines by consumers. More precisely, we consider a set of nutrient-based (salt, SFA) and food-based (F\&V, meat) dietary recommendations, determine the substitutions within the consumers' diet induced by their adoption, and estimate the loss of welfare (taste costs) induced by these changes. To deal with the health issue, we match the economic model with an epidemiological one, and assess the health impacts of diet changes in terms of chronic diseases prevalence and mortality. Similarly, to deal with the environmental issue, we estimate the effects of the diet changes on environmental indicators. By confronting the consumers' taste costs and the health and environmental outputs, we finally proceed a costbenefit analysis of dietary recommendations.

In section 2 , we briefly present the theoretical model. In section 3 , we present the data and the empirical methods used to simulate the impact of various dietary recommendations on diets, welfare, environment and health. In section 4, we present the empirical results for a set of food-based and nutrient-based recommendations. In section 5, we assess the robustness of our results. Section 5 concludes the paper.

\section{The Behavioural Model}

The main building block of the analysis is a model of dietary adjustment under nutritional and/or environmental constraints (henceforth simply referred to as "dietary constraints"), which was first proposed to investigate the economics of nutritional recommendations by Irz et al. (2015). Making the assumption that the environmental impact of food consumption is linear in the quantities consumed, as is implicit in Life Cycle Analysis (Ekvall et al., 2007), extension of the model to the environment sphere is methodologically straightforward. The approach is based on the assumptions of utility maximization and economic rationality of consumers. Thus, observed consumption choices are those which, given prices and income, maximize utility, and any exogenous changes, for instance in prices, induce adjustments in optimal consumption choices. The strong assumption of rationality also implies that consumers have full knowledge of product characteristics and prices when making decisions. This paradigm, even if based on strong simplifying assumptions, has proved its usefulness and accuracy in the analysis of consumer choices. However, we acknowledge that alternative and legitimate views, for instance that consumption behaviours are primarily reasoned or automatic, have also been proposed to explain food choices, and that, at this stage, none of those three views can claim superiority in the ability to explain human behaviour (Grunert et al., 2012; Köster, 2007).

Formally, we adopt the conventional framework of neoclassical consumer theory by assuming that an individual chooses the consumption of $H$ goods in quantities $x=\left(x_{1}, \ldots x_{H}\right)$ to maximize a strictly increasing, strictly quasiconcave, twice differentiable utility function $U\left(x_{1}, \ldots x_{H}\right)$, subject to a linear budget constraint $p . X \leq M$, where $p$ is a price vector and $M$ denotes income. However, departing from the standard model, we now assume that the consumer operates under $N$ additional linear constraints. Those constraints could, for instance, correspond to a maximum permissible $\mathrm{CO}_{2}$ equivalent from the diet, a maximum consumption of meat, or, in the nutrition domain, maximum levels of consumption of "unhealthy" foods or nutrients (e.g. salt, saturated fat). Denoting by

$a_{i}^{n}$ the constant nutritional or environmental coefficient (henceforth referred to as technical coefficient) for any food $i$ and target $n$, the value of which is known from LCA databases or food composition tables, the dietary constraints are expressed by: 


$$
\sum_{i=1}^{H} a_{i}^{n} x_{i} \leq r_{n} \forall n=1, \ldots, N
$$

Solving the Hicksian Problem - The utility maximization problem under budget constraint and multiple linear constraints (1) is difficult to solve directly so that, following Jackson (1991), we first focus on its Hicksian counterpart. We denote the compensated (Hicksian) demand functions of the non-constrained problem by $h_{i}(p, U)$, and those of the constrained model by $\tilde{h}_{i}(p, U, A, r)$, where $A$ is the $(N \times H)$ matrix of technical coefficients, and $r$ the $N$-vector of maximum levels of the constraints. We then introduce the notion of shadow prices $\tilde{p}$, defined as the prices that would have to prevail for the unconstrained individual to choose the same bundle of goods as the constrained individual: $\tilde{h}_{i}(p, U, A, r)=h_{i}(\tilde{p}, U)$. As shown in Jackson (1991) and Irz et al. (2015), those shadow prices are solutions of the following non-linear system:

$$
\begin{array}{lr}
\tilde{p}_{i}=p_{i}-\sum_{n=1}^{N} \mu_{n} a_{n i} & i=1, \ldots, H \\
\sum_{i=1}^{H} a_{i}^{n} h_{i}(\tilde{P}, U)=r_{n} & n=1, \ldots, N<H
\end{array}
$$

where $\mu \geq 0$ is the $N$-vector of Lagrange multipliers associated with the $N$ dietary constraints in the expenditure minimization problem, and $P$ is the $H$-vector of shadow prices. The first set of equations (2a) is easily interpreted: each shadow price is the sum of the actual price and a sum of terms depending on the nutritional/environmental coefficients of each food, as well as the influence of each constraint on minimum expenditure as measured by the Lagrange multipliers. In general, system (2) is highly non-linear and cannot be solved analytically, but we circumvent that problem by deriving relevant static comparative results describing, at the margin, the relationship between food demand and dietary constraints. In the case of $\mathrm{N}$-linear constraints, this requires the introduction of some notations. We first partition the $N x H$ matrix of environmental and nutritional coefficients $A$ into a square matrix $B$ and a residual matrix $C$ as follows:

$$
A=\left(\begin{array}{ccc}
a_{11} & \cdots & a_{1 H} \\
\vdots & \ddots & \vdots \\
a_{N 1} & \cdots & a_{N H}
\end{array}\right)=(B C) \text {, where } B=\left(\begin{array}{ccc}
a_{11} & \ldots & a_{1 N} \\
\vdots & \ddots & \vdots \\
a_{N 1} & \cdots & a_{N N}
\end{array}\right) \text { and } C=\left(\begin{array}{ccc}
a_{1 N+1} & \cdots & a_{1 H} \\
\vdots & \ddots & \vdots \\
a_{N N+1} & \cdots & a_{N H}
\end{array}\right)
$$

Irz et al. (2015) derive an expression showing the change in the vector of shadow prices resulting from a marginal change in the constraint levels $r$ :

$$
\frac{\partial P}{\partial r}=\left(\begin{array}{c}
{\left[A \cdot S \cdot\left(\begin{array}{c}
I_{N} \\
C^{\prime} \cdot\left(B^{\prime}\right)^{-1}
\end{array}\right)\right]^{-1}} \\
C^{\prime} \cdot\left(B^{\prime}\right)^{-1} \cdot\left[A \cdot S \cdot\left(\begin{array}{c}
I_{N} \\
C^{\prime} \cdot\left(B^{\prime}\right)^{-1}
\end{array}\right)\right]^{-1}
\end{array}\right)
$$


where $I_{N}$ denotes the $N x N$ identity matrix, and $S$ is the familiar $H x H$ matrix of Slutsky coefficients (i.e., $\left.s_{i j}=\partial h_{i} / \partial p_{j}\right)$. The corresponding adjustments in Hicksian demands resulting from the same marginal change in the levels of the constraints follow immediately:

$$
\frac{\partial h}{\partial r}=\frac{\partial h}{\partial P} \frac{\partial P}{\partial r}=S \cdot \frac{\partial P}{\partial r}
$$

Expressions ( 3 ) and (4) fully characterize the dietary adjustments, in an Hicksian framework, as a function of two sets of parameters only: first, the Slutsky matrix $S$ describes consumer preferences and measures the relative ease or difficulty of substituting foods for one another; and, second, matrix $A$ gathers technical coefficients expressing the properties of each food in the nutritional and environmental domains. Given that the Slutsky matrix is typically estimated empirically from observations on actual purchase behaviours, we claim that the model is therefore based on realistic food preferences, unlike virtually all programming-based models of diet optimization that make arbitrary assumptions about food preferences, either explicitly (i.e, by imposing "palatability constraints") or implicitly (through the choice of an arbitrary objective function).

More generally, expressions (3) and (4) show that a change in the nutritional constraints has an impact on the entire diet. This is true even for the goods that do not enter the constraints directly, as long as they entertain some relationship of substitutability or complementarity with any of the goods entering the constraints (i.e., as long as at least one Slutsky term $s_{k i}$ is different from zero). Further, the model indicates that the magnitude and sign of any change in demand for any given product is unknown a-priori but depends in a complex way on the product's technical coefficients and its substitutability with other products entering the constraints.

From an empirical perspective, what is important is that equations (3-4) can easily be calculated by combining a matrix of Hicksian demand parameters to a set of easily available technical coefficients. Hence, assuming that we have a matrix of price elasticities describing the behaviour of an unconstrained individual, equations (3-4) provide a means of inferring how that individual would modify his diet in order to comply with the imposition of dietary norms at the margin (e.g., how his/her consumption of any food would respond to, for instance, a reduction in the maximum permissible level of $\mathrm{CO}_{2}$ equivalent emanating from his/her diet).

From Hicksian solution to Marshallian solution - The Hicksian problem solved above is a useful theoretical construct but real-world consumers operate under a budget constraint rather than a utility constraint, and policy simulations of the effects of dietary recommendations therefore require calculation of the associated Marshallian solution. In pursuit of that goal, we first calculate the short-run private welfare $\operatorname{cost}^{1}$ of satisfying the constraints as measured by the compensating variation $C V$. By definition, the compensating variation is the difference between the initial expenditure (more generally the initial wealth) and the expenditure that maintains the utility constant in the nutritionally-constrained problem. Note that in the constrained problem, final expenditure is evaluated at market prices (as prices do not change). The compensating variation is thus also a

\footnotetext{
${ }^{1}$ This welfare measure is "short-run" because it ignores the long-run health effects, and it is "private" because it ignores the external environmental cost. Those effects are taken into account in the empirical analysis, in which we calculate the costeffectiveness of the recommendations.
} 
measure of the taste cost of the constraints. We have $C V=C(p, U)-\tilde{C}(p, U, A, r)$, where the two $C($. functions denote the minimum expenditure functions of the unconstrained and constrained problems respectively. Irz et al. (2015) show that the $C V$ is calculated for any change in any of the constraint levels $r_{j}$ as:

$$
C V=-\sum_{i=1}^{H} p_{i} \frac{\partial \tilde{h}_{i}}{\partial r_{j}}
$$

Clearly, since the constrained solutions $h$ belong to the choice set of the unconstrained problems, $p . h \geq p . h$, and the $C V$ is always negative. In absolute value, it represents the increase in the food budget necessary to maintain utility constant when the dietary constraints are imposed, or in other words the level of the compensation that would make the consumer indifferent between his original diet and the diet satisfying the constraints. It follows that an approximate solution to the change in Marshallian demand $\Delta x$ can be calculated from the change in Hicksian demand $\Delta h$ and the income effect associated with the removal of the compensation:

$$
\Delta x-\Delta h=\tilde{h} \cdot \varepsilon^{R} \frac{C V}{p \cdot \tilde{h}}
$$

In this expression, $\varepsilon^{R}$ denotes the vector of income (or expenditure) elasticities, which is empirically estimable, while the ratio $C V / p . \tilde{h}$ measures the negative percentage change in the food budget corresponding to the removal of the compensation. All the other terms are either observed (prices, consumption levels) or calculated from equations (3), (4) and (5).

At a conceptual level, our model implicitly assumes the additive separability of the utility function in terms of health and consumption. This allows us to define the short-term sub-utility function $U($.) upon which the taste cost is built. Following the provision of more information, this short-term utility function remains unchanged, as the consumer does not modify her valuation of short-term rewards from food consumption (e.g., hedonic rewards, convenience). Instead, we consider that information affects behaviours through changes in the subjective probabilities of adverse health outcomes linked to consumption patterns. Thus, as a result of a recommendation and its promotion, the consumer modifies his arbitrage between short-term rewards from food consumption and long term reward from improved health. In the short term, this adjustment has a welfare cost, which we measure and identify as 'taste cost'. The long term health impact is measured the aggregate level of the population in terms of deaths avoided (DA).

\section{The Empirical model}

The behavioural model presented in the previous section is applied to estimate the variation in household consumption induced by the adoption of health-based and environmentally-based dietary recommendations for different representative households of the French population. In a second step, this variation in household consumption is translated into changes in individual food and nutrient intakes. The health effects are then assessed by using the epidemiologic DIETRON model, which permits estimation of the changes in mortality attributable to a change in diet in a given population. On the environmental side, changes in diets are converted 
into changes in environmental indicators using appropriate LCA-based technical coefficients. Finally, the effects of the recommendations on health, private welfare, and the environment are brought together in the analysis of the relative cost-effectiveness of different recommendations. As the model calibration was presented in detail in Irz et al. (2015), we summarize below the empirical procedure rather concisely, insisting mainly on the new elements of the analysis related to the choice of constraints, the introduction of the environmental constraints, as well as the welfare assessment integrating environmental externalities.

Choice of Recommendations - The choice of dietary constraints to be analysed is based on commonly formulated recommendations justified on health and/or environmental grounds, as well as previous analyses of the sustainability properties of diets. An overarching objective is to assess whether synergies or trade-offs exist between the two sustainability dimensions (e.g., can recommendations promoting healthier diets be expected to also generate environmental benefits, and vice versa?). We first select four healthy diet recommendations because of their well-established potential to improve public health:

- Promotion of fruits and vegetables has been actively pursued in many countries, for instance through social marketing campaigns of the "five-a-day" type (Capacci and Mazzocchi, 2011; Silva et al., 2013).

- Reduction in salt intake is a common aim of public health nutrition campaigns (Shankar et al., 2013).

- Reduction in saturated fat intake remains at the core of most healthy diet recommendations (WHO, 2003; DGAC, 2015).

- Excessive intake of sugar is increasingly regarded as a serious public health issue. For instance in the UK, the Scientific Advisory Committee on Nutrition (SACN) has recently concluded that the recommended average population maximum intake of sugar should be halved (Public Health England, 2015)

In addition, the analysis of nutritional recommendations of Irz et al. (2015) concluded that targeting the first three food groups or nutrients was the most cost-effective strategy.

On the environmental side, the climate change issue currently dominates the debate about food consumption (Macdiarmid et al., 2012) and we therefore select a constraint on the $\mathrm{CO} 2$ equivalent of the diet, which is a summary measure describing how much global warming can be expected from consumption of that diet. Translating a reduction in greenhouse gas emissions into food-based recommendations usually results in prescriptions to reduce consumption of meat, most notably from ruminants. We therefore consider two related scenarios in the empirical analysis (namely, all meat and red meat). Altogether, this gives us a total of seven recommendations to be examined empirically. For each recommendation, we simulate the impact on food choices of the adoption of a recommendation that modifies the related constraint by $5 \%$ (e.g., $5 \%$ increase in consumption of $F \& V, 5 \%$ decrease in CO2e emissions etc.).

Initial diet and behavioural parameters - The behavioural model is calibrated using KANTAR Worldpanel data from a panel of 19,000 representative consumers of the French population. Food consumption is aggregated into 22 categories, which are defined on pages 2-3 of the supplementary material of Allais et al. (2010) and are largely self-explanatory. The behavioural parameters necessary to estimate the model, namely a full set of price and expenditure elasticities corresponding to those 22 aggregates, are also drawn from Allais et al. $(2010)^{2}$ for four

2 See http://ajae.oxfordjournals.org/content/suppl/2010/01/23/aap004.DC1/aap004supp.pdf. The price elasticities for the four income groups are reported in Tables 7-10 of that document and the expenditure elasticities in Table 6. 
representative types of households differentiated according to income quartiles and henceforth referred to as "Modest", "Lower average", "Upper average", and "Well-off".

Technical coefficients of the food aggregates - The nutrient contents of the 22 food aggregates, which are needed to formulate the health constraints and simulate health effects, are calculated by combining the food composition database of the French dietary intake survey INCA2 ${ }^{3}$ and average adult intakes of the component foods of each aggregate drawn from INCA2. They have already been published as Table A.1 in Irz et al. (2015).

On the environmental side, GHG emissions (expressed in grams of carbon dioxide equivalent units), and air acidification (in grams of sulfur dioxide equivalent units) have been calculated in a French collaborative research project (Bertoluci et al., 2016). The estimates of environmental impacts include the results associated with each stage of the production, transformation, packaging, distribution, use, and end-of-life of food products. The method used to compute and validate GHGE estimates of foods consumed in France combines a Life Cycle Analysis (LCA)-based approach and a top-down Input-Output approach. LCA is the most widely recognized reference method to estimate environmental impact of food products. Its generic methodology and principles for implementation are defined by the ISO $14040^{4}$ and 14044 international standards. As demanded by those standards, many elements must be specified, such as the perimeter of the model, the functional unit considered, and the size and nature of the cut-off applied. However, the detailed LCA of just one existing product requires important resources and time. To produce reliable estimates for a wide range of products, specific markets, and periods of time, it has been proposed to hybridize data from LCA with those of top-down approaches such as Input-Output (IO) matrices. The IO method offers a framework for allocating the environmental impacts caused by industrial product categories for a specific region. In addition, national commercial data about imports and exports allow consideration of the geographical origin of food products as well as their transport impacts. The use of this type of data allows to define a realistic model of the national market in terms of the geographical origin of the food products consumed in France.

Simulation procedure for the behavioural model - We simulate the impact of a marginal change in the levels of the dietary constraints on Marshallian demands by applying an iterative procedure based on equations (3) to (5):

1- Given a $5 \%$ exogenous change $\Delta r$ in the level of the constraints, we calculate the resulting changes in Hicksian demands through (3-4).

2- The quantities thus obtained and original prices are then combined to calculate the compensating variation (5) linked to the imposition of the change in constraint levels.

3- This compensation, which hypothetically would allow the consumer to maintain his utility level, is then removed to calculate the corresponding changes in Marshallian demands through (6). However, because the constraints are directly imposed on the Hicksian demands rather than Marshallian demands, there is no guarantee that the diets calculated in step 3 comply with the original set of constraints. The search for the solution therefore proceeds as follows.

\footnotetext{
3 INCA2 stands for "Étude Individuelle Nationale des Consommations Alimentaires 2006-7".

${ }^{4}$ ISO 14040, 2006, Environmental Management-life Cycle Assessment - Principles and Framework, (second ed.) (2006) Geneva, Switzerland
} 
4- Calculation of the level of the targeted food/nutrient/environmental indicator resulting from the Marshallian demands in step 3. If this Marshallian solution satisfies the constraints, it is kept as the final solution of our problem.

5- If the Marshallian solution does not satisfy the recommendation, we go back to the first step by adjusting the level of the starting constraints.

This iterative process ends when the Marshallian solution calculated in step 3 satisfies the constraints (as calculated in step 4).

Health and environmental impacts - Simulation of health effects first requires that changes in food consumption at household level, as described by the behavioural model, be translated into changes in individual intakes, distinguishing between males and females ${ }^{5}$. This is accomplished under the assumption that (i) the percentage changes in intakes are the same for all the members of a given household, and (ii) the percentage changes are the same for at-home and out-of-home consumption ${ }^{6}$, and using the INCA2 dietary intake database. Changes in food intakes are converted into changes in nutrients using the nutritional coefficients of the 22 aggregates, and those are then translated into changes in mortality due to diet-related chronic diseases by using the DIETRON epidemiological model of Scarborough et al. $(2012)^{7}$.

The parameters of the DIETRON model are derived from world-wide meta-analyses of dietary risk factors and are not country specific, so that adapting the DIETRON model to France only requires calibration of the initial mortality levels, by relevant causes. This is achieved by using the INSERM data on mortality in France attributable to major diet-related diseases. We limit the study to individuals between the age of 25 and 74 and therefore focus on the effects of dietary changes on premature deaths (i.e., occurring before the age of 75). The baseline numbers of deaths according to each disease and each income class are published in Table 3 of Irz et al. (2015), which shows that the diseases considered in DIETRON account for slightly more than one third of total French mortality.

In addition to the mean value of the different relative risks, the DIETRON model also provides the distributions of each relative risk parameter. Twenty-six of those follow log-normal distributions and six follow normal distributions, while all are independent. We perform 251 Monte Carlo simulations by drawing a set of parameters one million times. To be more precise, for a given type of consumer, we draw a set of 32 parameters, use this set to evaluate the number of DA for each nutritional recommendation and repeat the operation one million times. In the results section, we provide the median as well as the 2.5 and 97.5 percentiles of DA for each recommendation.

The environmental indicators are calculated by applying the previously mentioned constant LCA-based coefficients for each food to measured or simulated dietary intakes. To take into account the uncertainty

\footnotetext{
${ }^{5}$ Hence, the health model considers 8 types of individuals (i.e. 4 income groups $* 2$ genders).

${ }^{6}$ The dietary intake database covers all the foods consumed by an individual whereas the Kantar database only covers athome consumption.

${ }^{7}$ More precisely, the dietary input data for the health model are intakes of: total energy (MJ/day); fruit (g/day); vegetables (g/day); fibers (g/day); total fat (\% total energy); mono unsaturated fatty acids (\% total energy); polyunsaturated fatty acids (\% total energy); saturated fatty acids (\% total energy); dietary cholesterol (\% total energy); salt (g/day) (Scarborough, Allender et al., 2012).
} 
surrounding the GHGE estimates, we assumed, in line with Vieux et al. (2013), that GHGE estimates for each food category followed log-normal distributions with larger dispersions for animal-based products $(-25 \%$ of the median value at the 2.5 percentile; $+30 \%$ of the median value at the 97.5 percentile) than for the other products (-20\% of the median value at the 2.5 percentile; $+20 \%$ of the median value at the 97.5 percentile). We also assumed that the distributions of the GHGE coefficients of the different food groups were independent. We then calculated the GHGE impact of the diets induced by the adoption of the various constraints by drawing $10^{6}$ times GHGE values for each food group. The same method was applied for acidification values.

The results are presented in Table 1 for the initial (observed) average French diet across different gender and income groups. The calculated levels of $\mathrm{CO} 2$ eq. from the diet are consistent with the population average of 4092g/day reported by Vieux et al. (2012). For both pollutants and each income group, men are responsible for more emissions than women, which we explain by their larger energy intakes. There is a slight socio-economic gradient for GHGEs, with a positive association with income, which is not observed for $\mathrm{SO} 2 \mathrm{eq}$.

[Table 1 here]

Cost-effectiveness analysis - Our model calculates the effects of dietary adjustments under an "as if" assumption, i.e. assuming that the consumer complies with the exogenously given change in the constraint level(s). In practice, however, behavioural change is difficult and requires public investment in social marketing campaigns and other types of interventions, with uncertain effectiveness. For this reason, our welfare assessment of alternative recommendations shies away from attempting to measure the cost of ensuring compliance with a given recommendation/constraint, but instead investigates a different question: what is the maximum amount that could be invested to promote a given recommendation so that the outcome would remain socially desirable (i.e., would increase social welfare)?

Promotion of a given set of recommendations generates benefits, in terms of improved health of the population (denoted $B_{h}$ ) and reduced environmental externalities (denoted $B_{e}$ ), as well as costs both to individuals (i.e., the taste cost as measured by $-C V$ and capturing a loss of hedonic rewards) and the public sector (i.e, cost of interventions such as social marketing campaigns, denoted $C_{p}$ ). The cost effectiveness threshold of each recommendation is hence calculated as $C_{p}=B_{e}+B_{h}+C V^{8}$, giving us a means of comparing the relative efficiency of all the selected recommendations.

The health benefit is quantified by applying a monetary value to the reduced mortality figures calculated by DIETRON. The starting point of the valuation is the threshold value of a Quality Adjusted Life Year (QALY) that is applied in the UK to investigate the cost-effectiveness of medical care (e.g., drugs, procedures). That threshold, discussed in McCabe et al. (2008) and still recommended by the UK National Institute for Clinical Excellence (NICE), lies within the $£ 20-30 k$ range, which translates roughly into $€ 24-36 k$ at the current exchange rate. ${ }^{9}$ Given that epidemiological data show that the average number of Life Years Saved (LYS) per DA is larger than 10 for most causes of mortality covered by DIETRON, we make the conservative assumption of 10 QALYs per DA, which

\footnotetext{
${ }^{8}$ As previously mentioned, $\mathrm{CV}$ is negative.

${ }^{9}$ Wolff and Orr (2009, p. 10) also report for the UK QALY values ranging from $f 30 k$ to $f 80 k$ across government departments.
} 
implies a value of a DA in the $€ 240-360 \mathrm{k}$ range. Leaning on the side of caution, we select the lowest value in this range, and our first valuation of health benefits should therefore be treated as a lower bound.

An alternative to QALYs for the valuation of DA is to use the value of a statistical life (VSL), defined as the effort, in terms of the resources used, that society is willing to make in order to reduce the risk of death. The VSL is commonly used in economic and policy analysis (see Treich, 2015, for a review). For instance, in the transportation area, the VSL reported by Anderson et al. (2011) range from 1.8 million USD 2005 for New-Zealand to 3.3 million USD 2005 for the United States, with the three represented EU countries using values in the order of 2 million USD 2005. Although there is continuing debate related to the correct value of a statistical life (Doucouliagos et al., 2012), it is clear that all those values greatly exceed the $€ 24 \mathrm{k}$ figure derived above from QALYs. Thus, we complete our analysis by also estimating benefits from a value of a DA more compatible with the VSL commonly used in decision making in the transport sector, namely $€ 1$ million.

On the environmental side, valuing the benefit of reduced externalities presents its own set of challenges. Regarding climate change, the European Union has initiated the world's largest carbon market, the Emission Trading Scheme (ETS), but it is widely regarded as dysfunctional (Stratham, 2013). The carbon price on that market peaked at $€ 30 /$ ton in 2008 but has shrunk as low as $€ 4 /$ ton in recent years, with this low price reflecting political failure and associated over-allocation of permits rather than the real value of carbon (Drew, 2008). In addition, some of the values used in policy assessment may ignore the biggest risks associated with climate change, and downplay the impact of current emissions on future generations. Ackerman and Stanton (2012) claim that, in a US context, inclusion of those considerations would boost the price of carbon from the widely used value of $\$ 21 /$ ton to $\$ 900 /$ ton. In the face of so much uncertainty, we rely on the meta-analysis of the social cost of carbon developed by Tol (2012). That author, after fitting a distribution of 232 published estimates, derives a median of $€ 32 /$ ton, a value which we adopt in our baseline analysis due to its rigour and objectivity. However, our sensitivity analysis also uses the value of 95-percentile of the distribution fitted by Tol (2012), which is equal to $€ 185 / \mathrm{t}^{10}$.

In the case of $\mathrm{SO} 2$, there is no market for emissions within the $\mathrm{EU}$ and the literature measuring shadow prices is dominated by US studies. Hence, of the twelve shadow prices reported by Dang and Mourougane (2014, Table 1), only one originates from an EU country (Germany, in 1995) and none from France, while the range of reported estimates is extremely large. One of the most rigorous and recent studies for the US is Mekaroonreung and Johnson (2012), who show how shadow prices depend on the choice of estimation method, and conclude to the superiority of non-deterministic methods on the basis of the compatibility of the estimated shadow prices with observed market prices. The preferred method results in shadow prices lying between 201 and 343\$/ton, which translates into a range of 176 to $300 € /$ ton. We use the mid-point of this bracket (€238/t) in our welfare assessment.

\section{Results}

\footnotetext{
${ }^{10}$ We note that this high value is of the same order of magnitude as the highest tax currently implemented in the world (namely, 168USD/t in Sweden, which is equivalent to $€ 148 / t$ - see World Bank's background notes on the carbon tax available online at: http://www.worldbank.org/content/dam/Worldbank/document/SDN/background-note_carbontax.pdf).
} 
The methodology is applied to simulate the effect on food consumption, nutrient intake, health, environment, short-run welfare and cost effectiveness of six different dietary constraints. In each case, the relative variation in the level of the constraint is five percent of its baseline level, and the direction is chosen so as to increase dietary quality (i.e., to reduce the maximum permissible level of relatively unhealthy nutrients/foods and increase the minimum permissible level of relatively healthy ones) or to lower the environmental footprint of food consumption.

Dietary adjustments and their impact on short-run welfare - We start with the impact of the different recommendations on food consumption, focusing on the "lower average" income group of households (Table 2). The decision to focus on this income group to report the first set of results is largely arbitrary, but the main results reported below are not dependent on that choice, and the corresponding results for the other three household types are presented in Appendix A, Tables A.1-A.3. Each column of Table 2 corresponds to a different constraint and presents two sets of percentages: the baseline contribution of each food group to the constrained quantity (i.e., food/nutrient/CO2eq) on the left, and the change in consumption resulting from the imposition of the constraint on the right. For the food-based constraints, it follows by construction that most of the baseline level of the constraint is accounted for by a narrow range of food products, even if we note that $6 \%$ of meat consumption originates from ready meals. By contrast, in the case of some nutrients such as sodium or in the case of the $\mathrm{CO} 2$ constraint, the contributions of the different food groups to the baseline level of the constraint are much more spread out in product space.

Turning to the results of the simulations, and focusing on the 'all meats' constraint, let us note at the outset that a five percent decrease in meat consumption corresponds to a daily consumption decrease of about $8 \mathrm{~g} /$ day. As shown in Table 2, imposition of this small variation in the constraint level results in relatively important changes in consumption of several food aggregates: the decrease in meat consumption is associated with a decrease in consumption of starchy foods $(-2.2 \%)$ whereas consumption of dairy products increases $(+3.4 \%) .{ }^{11}$ Hence, the relations of complementarity and substitutability among food products captured by the model appear quantitatively important, which already suggests that simulating the health and environmental effects of dietary recommendation under a "ceteris paribus" assumption (i.e., assuming here constancy of the diet except for the decreased consumption of meat) would be inappropriate.

Considering the simulation results at a higher level of product disaggregation in Table 2, we note that some complex substitutions also occur within product groups. For instance, within the F\&V group, the all meat constraint induces an increase in fresh fruit consumption as well as dry fruits consumption whereas the consumption of other products (processed fruits, F\&V juices, and vegetables) decreases. Among animal products,

\footnotetext{
${ }^{11}$ Note that the decrease in consumption of the 'all meats' category is different from $5 \%$ (the target for an increase in the total consumption of meats). This is because the ready meals category also includes some meat. Then, the total change in meat consumption takes into account the changes in consumption of the 'meat' category as well as the changes in the consumption of the other food categories, which contain some meat. A similar mechanism is evident with the F\&V constraint: imposing a $5 \%$ increase in consumption of all $F \& V$ results in a $5.9 \%$ increase in the consumption of the ' $F \& V$ ' food group. This is because some F\&V are included in the 'ready meals' food group, and the consumption of ready meals decreases by $11.7 \%$. Then the change in total $F \& V$ consumption takes into account the change in consumption of the ' $F \& V$ ' food group as well as ready meals.
} 
fish consumption (7.5\%) increases which could be expected but more surprisingly egg consumption (-3.3\%) decreases. Consumption of the different categories of dairy products also increases.

[Table 2 here]

The consumption changes associated with the imposition of the other constraints are rather varied and difficult to summarise. However, for food-based constraints the results indicate that, compared to the simulated effect described above with regard to the all meat constraint, imposition of the constraint on red meat results in smaller adjustments in food consumption. This is understandable as this constraint is less demanding in the sense that it concerns a smaller fraction of the diet and substitution with other meats occurs leading to a small decrease in 'all meats' consumption (-0.7\%). As compared to the constraint on all meats, the impact of this constraint on the other groups of food is of lower magnitude but in the same direction. In the contrary, imposing an increase in F\&V consumption leads to important changes in the diet. In particular consumption of starchy products (-16\%) and salt-fat products $(-21 \%)$ are strongly affected.

The results relative to the nutrient-based or environment-based constraints are also heterogeneous. In particular, the constraint imposed on $\mathrm{CO} 2$ leads to large changes in the diet. Changes at food group level are generally large (e.g all meats $(-8 \%)$, starchy food $(-12 \%), F \& V(+9 \%)$, dairy products $(-5 \%))$ and at the product category level they are even larger. Consumption of animal products are negatively affected whereas F\&V consumption is favored as well as the consumption of relatively energy dense foods such as salt-fat products or beverages. On the whole the consumer decreases consumption of products with a 'high' CO2 impact and increases the consumption of products with a 'low' $\mathrm{CO} 2$ impact. Surprisingly given that those products have a rather low $\mathrm{CO} 2$ impact, the consumption of starchy products decreases. This is the result in the model of complementarity and substitutability relationships among food products. Significant adjustments in consumption occur as a result of the imposition of the SFA constraint, which induces a reduction in consumption of dairy products and, at the same time, has differentiated impacts on the consumption of other animal products. Thus the consumption of red meat, cooked meat and eggs decreases whereas the consumption of other meats increases. In the case of the sodium constraint, the diet is significantly affected with a decrease in the consumption of the product categories that contribute most to salt intake (cooked meats, grains, cheeses, and salt-fat products). Finally, in the case of the added-sugar constraint, the consumption of soft-drinks significantly decreases (-19.2\%) whereas the consumption of beverages without added sugar (water as well as F\&V juices) increases. The consumption of sugar-fat products is much less impacted $(-4.0 \%)$ even if this group of products represents $57 \%$ of the initial intake of added sugar. This is because the demand for those products is relatively inelastic.

Overall, the simulations reveal that compliance with diet recommendations by a rational consumer implies large changes in consumption patterns, whose economic, health and environmental effects can only be adequately assessed by considering adjustments in the whole diet. Those complex adjustments reflect the nature of consumers' preferences for foods and would not have been possible to anticipate at the outset.

To further understand how the model works, the percentage differences between shadow prices associated with each constraint and actual prices are given in Table 3 for the same "lower average" household type. Focusing on the 'all meats' constraint, we note that the shadow prices of all the food products containing meat are larger than actual prices in order to encourage lower consumption, as expected. However, the table also reveals that 
the relative differences between shadow and actual prices are larger for meat products (ranging from $9.8 \%$ to 13.3\%) than for ready meals (3.3\%). From the theory section, we know that, for a given consumer, the shadow price of a product is a function of: a) the cost of the constraint $\mu_{n}$ in equation (2a), which depends itself on substitution possibilities and other characteristics of food preferences; $b$ ) the meat content of the product; and c) its actual price. The difference between shadow and actual prices is then greater for meat products than for ready meals as their content in meat is low. In the case of a constraint on red meat consumption, the difference between shadow and actual prices is much lower than in the previous case. This is because the elasticity of demand for red meat demand is larger than that for all meats. In the case of red meat, there are relatively close substitutes (the other meats) whereas it is not the case for 'all meats'. It is thus easier for the consumer to reduce consumption of red meat than consumption of all meats. In the case of the $F \& V$ constraint, the relative difference between shadow and actual prices is negative as the constraint is designed to raise consumption. Moreover, its magnitude is quite large.

For the nutrient-based or $\mathrm{CO} 2$ recommendations, the shadow prices of most products differ from actual prices, simply indicating that those nutrients (or $\mathrm{CO} 2$ ) originate from a wide range of foods. For all these constraints, we observe that some of the differences are large (i.e., at least $20 \%$ ) for several product categories, which suggests that part of the substitutions required to satisfy the constraint is relatively difficult. This is particularly the case for the $\mathrm{CO} 2$ recommendation as most differences are larger than $20 \%$ and can reach $80 \%$, meaning that reducing the $\mathrm{CO} 2$ footprint of the diet is difficult. ${ }^{12}$ The large differences between shadow and actual prices make intuitive sense: for instance, the constraint on saturated SFA implies a large shadow price of the oil group, and cheeses and butter, the sodium constraint is associated with a high shadow price of salt-fat products and the added sugar constraint is associated with high shadow prices of soft-drinks, processed fruits and sugar-fat products.

As a general remark, we note that Table 2 describes complex dietary adjustments which reflect the nature of consumers' preferences for foods and would not have been possible to anticipate at the outset. The robustness of those results ultimately depends on the robustness of the estimated elasticities, which are the key behavioural parameters driving the adjustment of the whole diet to a recommendation.

\section{[Table 3 here]}

The short-run welfare cost of satisfying the different constraints are measured by the compensating variations reported in the upper part of Table 4 . The short-run welfare cost of satisfying the red meat constraint is the lowest (10 M€) whereas the largest is associated with the CO2 constraint (961 M€) followed by the constraint on $\mathrm{F} \& \mathrm{~V}(466 \mathrm{ME})$ ). In relative term the short-run welfare costs are modest, as the cost of the CO2 constraint is only about $1.2 \%$ of the food budget. In most other cases, the relative welfare cost is smaller than half a percent of the food budget, and it is almost a negligible percentage for the constraints imposed on red meat and 'all meats'. However, before concluding to the insignificance of taste costs, one should keep in mind that the $5 \%$ variations in the levels of the constraints are also small - for instance, the decrease in 'all meats' consumption represents a decrease in consumption which is lower than $10 \mathrm{~g}$ per day. Further, the relative magnitudes of the CVs match the levels of dietary adjustments described in Table 2 and the differences between shadow and actual prices described in Table 3. Hence, the relatively large CV for the CO2 constraint is associated with large consumption

\footnotetext{
${ }^{12}$ At least when this reduction is interpreted as resulting from an implicit taxation scheme as implied by the methodology developed in the theory section.
} 
changes and large differences between actual and shadow prices, while the opposite is true for the constraint imposed on red meat. Those CVs, which capture the hedonic or taste cost of healthier or more environmentally friendly diets, have to be weighed against the associated health and environmental effects for a full assessment.

[Table 4 here]

Effects on nutritional and environmental indicators - The analysis of health and environmental impacts starts by converting the consumption changes described in Table 2 into changes in nutrients and environmental indicators, as presented for the whole population in Table 5. Imposition of the constraints induces substantial adjustments in the nutritional profile of the diet, but the overall change in diet quality remains ambiguous. For instance, the F\&V constraint induces desirable reductions in SFA, cholesterol, salt and energy intakes, but also an undesirable decrease in intake of fibers. Similar trade-offs in diet quality can be observed for all six constraints, which justifies pursuing the assessment of health impacts by applying DIETRON to translate those nutritional changes into unambiguous health outcomes (see next section).

The environmental impacts of the simulated dietary changes are characterized in Table 5 in terms of two indicators: greenhouse gas emissions (in equivalent $\mathrm{CO} 2$ ) and acidification (in equivalent $\mathrm{SO} 2$ ). With the exception of the recommendations on SFA and added-sugar, all recommendations lead to a decrease in the environmental impact of the diet, and we also note that the relative reduction in SO2eq. is generally larger than that in CO2eq. ${ }^{13}$ Hence, while our analysis reveals overall synergies between the pursuits of health and environmental goals (i.e., healthy eating recommendations tend to reduce the environmental footprint of food consumption), the results also indicate that those synergies do not occur systematically. Finally, as for the impact on nutrient intakes, the magnitudes of the changes in environmental indicators vary strongly across recommendations. In particular, recommendations on red meat or 'all meats' result in relatively small changes in environmental impacts, whereas the recommendations targeting $F \& V$ and CO2eq. generate larger environmental improvements. ${ }^{14}$

\section{[Table 5 here]}

Overall benefits and cost-effectiveness of the recommendations - We now bring together the economic, health, and environmental effects of the seven recommendations. First, DIETRON is used to aggregate the complex nutritional adjustments previously discussed into a clear health outcome: the number of deaths avoided within the whole population due to the reduced incidence of CHD, strokes, and ten different types of cancer. Four constraints are estimated to save more than 2000 lives annually (Table 4). This represents in each case a three to four percent decrease in the total mortality attributable to the diseases included in the DIETRON model, which can be considered substantial given the relatively small changes that are imposed exogenously (i.e., $5 \%$ change

\footnotetext{
${ }^{13}$ The exception is the recommendation on sodium.

${ }^{14}$ Of course, the latter occurs by construction. The reader should note that in Table 5, the composition of the diet in terms of SFA is expressed as a percentage of energy. Hence, the total change in SFA is the percentage reported in that row plus the percentage change in energy. In the case of the SFA constraint, this gives $-2.3 \%-2.5 \%=-4.8 \%$. This figure is not exactly equal to $5 \%$ because of: 1 - the approximation used to calculate the Marshallian solution described in section 3 ("Simulation procedure etc"); and, 2- the conversion of consumption changes into intake changes (as explained in Section 3, "Health and environmental impacts"). In the case of the $\mathrm{CO} 2$ recommendation, we also note a small difference between the target (-5\%) and the actual change (-5.3\%).
} 
in the constraint level). However, the two constraints on meat are also revealed to be relatively less effective in reducing mortality as they would save less than 250 lives annually, which is about ten times less than for the other four recommendations. Although the diet changes induced by these two recommendations targeting meat consumption are rather different, their overall impact on health is similar. The constraint on added sugar has an intermediate impact, as it is estimated that it would save less than 1000 lives annually. Table 4 also presents the total environmental impacts of the dietary changes by reporting variations in the indicators of global warming (CO2 eq.) and acidification (SO2 eq.) for the whole population.

To compare the efficiency of the alternative recommendations, our analysis then proceeds in two steps. First, we define partial indicators of efficiency, which balance the consumer cost against the health or environmental impact as measured by a single indicator (Table 4). In a second step we present in Table 6 the global costeffectiveness measure as explained in section 3.

The consumer cost per DA varies from $€ 45 \mathrm{k}$ for red meat and sodium recommendations to $€ 412 \mathrm{k}$ for the $\mathrm{CO} 2$ recommendation. Those results indicate that the (partial) cost-effectiveness of the recommendations varies enormously, and that the most effective recommendations are not necessarily those that save the most lives. In the case of red meat, the high level of partial cost-effectiveness is attributable to the particularly small taste cost of the recommendation, which is understandable given the minor dietary adjustments and associated changes in shadow prices that we already documented for that constraint. In other words, the utility cost of reducing red meat consumption is minimal, so that even if that reduction produces relatively limited health gains, its partial cost-effectiveness is very high. The constraint on salt achieves the same level of partial cost-effectiveness but this is the result of both a significantly larger short-run welfare cost and a larger impact on health. By contrast, on the basis of this partial analysis, promoting a recommendation to reduce GHGEs from food consumption is a very cost-ineffective way of reducing diet-related mortality. However, we also note that for all recommendations the cost per DA compares favourably with (i.e., is significantly smaller than) the VSL typically used in the evaluation of transportation projects (i.e., in excess of $€ 1$ million).

Turning to environmental impacts, the consumer cost per kiloton of $\mathrm{CO} 2$ avoided varies from $€ 38$ (red meat) to more than $€ 300$ ( $\mathrm{CO} 2$ eq.), except in the case of the recommendations targeting SFA or added-sugar, which have a negative environmental impact. When compared to the baseline estimate of the social cost of carbon discussed in the methodology section $(32 € / t)$, only the recommendation on red meat appears to approach partial costeffectiveness, although that recommendation results in a small absolute reduction in GHGEs. Even considering the high value for the price of carbon (i.e., the 95 -percentile value of $€ 185 / t$ ), the partial cost effectiveness of reducing GHGE by promoting dietary recommendations appears poor except for those recommendations targeting meat consumption. The results for $\mathrm{SO} 2$ are even worse in terms of partial cost effectiveness: reducing SO2eq. by one ton through dietary adjustment imposes a consumer cost varying from $€ 1442$ for the red meat constraint to more than $€ 17000$ for the salt constraint and even more than $€ 100000$ for the SFA constraint. Those values exceed all the reasonable estimates of the social cost of $\mathrm{SO} 2$ emissions.

[ Table 6 here ]

However, a complete assessment of the cost-effectiveness of the various recommendations requires that the multiple benefits and costs of each measure be considered jointly. Those population-level benefits, private costs, as well as the cost-effectiveness threshold $C_{p}$ that could be allocated to promote each recommendation while 
ensuring overall cost-effectiveness, are presented in Table 6. Given the difficulties in valuing health and environmental improvements discussed in section 3, the calculations are repeated in separate columns for different sets of parameters defined in the upper part of the table. For the lower bound of the value of a DA $(€ 240 \mathrm{k})$ and lower value of carbon $(€ 32 / \mathrm{t}$ ), the first column of results shows that it would be desirable to spend considerable annual amounts of resources to promote the recommendations targeting F\&V (€193 million), salt ( $€ 572$ million), SFA ( $€ 217$ million), added-sugar ( $€ 62$ million)and red meat ( $€ 55$ million) but not those targeting GHGEs and consumption of all meats. For the first five of those recommendations, we note that $C_{p}$ vastly exceeds the typical cost of running a social marketing campaign to promote dietary change. For instance, with regard to healthy eating, the ex-post evaluation of Capacci and Mazzocchi (2011) found an 8\% increase in F\&V consumption following a three-year "five-a-day" campaign in the UK at a cost of less than $£ 3$ million (roughly €4million). Hence, even using extremely conservative parameters to value health benefits, and taking into account the taste cost of dietary adjustment typically ignored in public health analysis, our analysis indicates that the F\&V, SFA, salt, added-sugar and red meat recommendations are likely to be highly cost-effective. If the benefit per DA is calculated from a value closer to the VSL ( $€ 1$ million), or if we use a high price of carbon (€185/t), all seven recommendations appear highly cost effective. In the case of the sugar-added recommendation, a high price of carbon decreases its cost effectiveness as this constraint leads to an increase in GHG emissions. Thus, in spite of the uncertainties surrounding both the valuation of non-markets goods/bads and the estimates of health and environmental impacts (cf. the 95\% confidence interval provided in Tables 5 and 6 ), the analysis points to the social desirability of allocating more public resources to the promotion of sustainable diet recommendations.

Table 6 can also support decision making by establishing a reasonably clear ranking of the recommendations to be promoted. For all scenarios, the recommendation targeting salt achieves the highest level of cost effectiveness, followed by the F\&V or SFA recommendation, depending on the choice of valuation parameters. Hence, the three recommendations justified mainly on health grounds are more efficient than those with purely environmental (e.g., $\mathrm{CO} 2$ eq.) or mixed (e.g., red meat, all meats) objectives. This result is investigated further in table 7, which presents the breakdown of the total benefit into its health and environmental components. With the exception of the "all meat" recommendation monetized using the low value of a DA ( $€ 240 \mathrm{k})$ and high value of $\mathrm{CO} 2(€ 185 / \mathrm{t})$, the health benefit from adjustments in the diet always exceeds the environmental benefit (this is also true when considering the confidence intervals). This is the case even though in absolute terms, the meat constraints, for instance, generate relatively small health benefits as measured by the total number of DAs in Table 4.

[Table 7 here ]

\section{Robustness of the results}

As it is the case for most empirical studies, it is important to discuss the robustness of the results when facing some uncertainty about the data. In our case, this issue arises with respect to the impacts of diet changes on GHG emissions. Even if LCA-based methods are used in many studies aiming to quantify contributions of consumers' diets to climate change, the estimates of GHG emissions related to specific foods remain uncertain. 
In order to assess the robustness of our results to the choice of LCA coefficients used in the empirical analysis, we rely on the study of Bertolucci et al. (2016) who compared two sets of coefficients. The first set of LCA coefficients, which we used in our simulations, was computed specifically for the French case using the hybrid method discussed in Section 3 ('COEFF 1' in the Tables below). The second set of coefficients was derived from a systematic review of the literature (70 references, most from peer-reviewed journals) ('COEFF 2' in the Tables below). In Table A.4 of the Appendix we provide a comparison of the two sets of GHG emission coefficients for our food groups. Even if the ranking of the food groups is very similar and the correlation between the two sets of coefficients appears high, Bertolucci et al. (2016) noted some discrepancies which could be caused either by the variability of LCA methods used in the literature, or by differences in production methods across countries. Significant differences appear in particular for meat and animal-based products, with the set of coefficients derived from the literature giving higher per unit GHGE impacts.

To take into account this uncertainty and then assess the robustness of our results in relation to the environmental coefficients used, we simulated the impacts of the adoption of the seven dietary constraints using the second set of coefficients estimated on the basis of a literature review by Bertolucci et al. (2016). Note that for all food- or nutrient-based recommendations, changes in diet are not modified by the change in LCA coefficients. As a consequence, the health impacts are the same for all those recommendations, regardless of the LCA coefficients used in the model. It is only the impacts on GHG emissions of the dietary adjustments which are modified.

In the case of the $\mathrm{CO} 2$ recommendation, modification of the LCA coefficients has deeper consequences: the dietary adjustments are modified because the GHGE coefficients of the food groups enter a constraint in the consumer program (i.e. the recommendation). As meat and animal-based products have higher impacts according to the second set of coefficients, a 5\% reduction in GHGE emissions from the diet can be obtained with smaller adjustments, especially a lower reduction in consumption of meat and other animal products consumption, leading to lower costs to consumers (460 versus $961 \mathrm{M} €$ ) but also smaller impacts on health. Thus the number of deaths avoided by complying with the $\mathrm{CO} 2$ constraint now amounts to 1688 while it was estimated to 2331 when using the first set of LCA coefficients. The cost per DA is lower when using the second set of coefficients (272 k€/DA as compared to $412 \mathrm{k} € / \mathrm{DA}$ ) but remains very high.

Obviously, even if dietary adjustments remain the same (except for the CO2 recommendation) when LCA coefficients change, the estimated GHGE impact of those adjustments is modified. We provide in Table 8 a comparison of impacts depending on the set of coefficients used. With the second set, most recommendations appear more efficient in reducing GHGE impacts than previously as they reduce consumption of meat and animal products that have higher GHGE values in the second set of LCA coefficients. An exception is compliance with the added sugar constraint, which results in an increase in GHGE impact of the dietary adjustment, as this constraint leads to an increase in the consumption of animal products. The important point, however, is that the ranking of the seven constraints in terms of reduction in environmental impact is not modified.

\section{[Table 8 here]}

Regarding environmental and health benefits (Table 9), for all constraints except those related to added sugar and $\mathrm{CO} 2$, the total benefit increases. It is understandable as the health benefit does not change and the 
environmental benefit increases in line with the higher LCA coefficients for animal products. In the case of the added sugar constraint, the impact on health does not change but the environmental damage increases. As a consequence the total benefit decreases and the cost-effectiveness threshold $\mathrm{C} p$ is lower. For high economic values of $\mathrm{CO} 2$, this recommendation must not be considered cost-efficient. In the case of the $\mathrm{CO} 2$ constraint, the increase in the environmental benefit is not sufficient to compensate the decrease in the health benefit (as the number of DA decreases), and then the total benefit decreases. However, as this constraint is now easier to satisfy by consumers, the taste cost is smaller and the cost-effectiveness threshold is larger. Therefore, it may be relevant to promote this recommendation even with low economic values of $\mathrm{CO} 2$.

As was the case with our first set of estimates, for most scenarios, the recommendation targeting salt, F\&V and SFA achieve the highest levels of cost effectiveness. However, for high economic values of $\mathrm{CO} 2$, the purely environmental recommendation targeting a 5\% decrease in $\mathrm{CO} 2$ emissions reaches a comparable level of costeffectiveness when the second set of LCA coefficients is used. In most cases, the health benefit from adjustments in the diet still exceeds the environmental benefit, with the exception of the "all meat" and "CO2" recommendations monetized using the high value of $\mathrm{CO} 2$ (result not displayed in the Table).

Overall, with this second set of coefficients according to which meat and other animal products have higher impacts on GHG emissions, our main conclusion is reinforced: most recommendations appear to be cost-efficient and the social desirability of allocating more public resources to the promotion of sustainable diet recommendations is confirmed. Moreover, the ranking of the different recommendations remains mostly unmodified.

[Table 9 here]

\section{Conclusion}

Ex-ante assessment of informational measures urging individuals to modify their food choices for health or environmental reasons requires a clear understanding of how whole diets might respond to these policies as foods are interrelated via complex relationships of substitutability and complementarity. In the present paper, we address this issue by proposing a whole-diet model to analyze changes in food choice when consumers are urged to comply with health and environmental dietary recommendations. This economic model, grounded in the theory of the consumer under rationing, is used to empirically estimate how the adjustments in one part of the diet, due to the adoption of such dietary recommendations, have potential consequences on the whole diet, and finally on health and environmental indicators.

This empirical analysis of a set of dietary recommendations contributes to the existing literature on sustainability of diets and the potential convergence of solutions to food-related health and environmental issues. However, in comparison with most of current approaches, our analysis takes a new step by explicitly taking into account consumers' preferences in the assessment of the effects of dietary recommendations. Indeed, unlike many other 
studies, the substitutions within the diet induced by the adoption of recommendations are endogenously defined on the basis of consumers' preferences expressed by price and expenditure elasticities.

The first contribution of this method is that it permits to calculate the 'taste' cost' incurred by consumers, that is, the loss of utility associated with the adoption of a dietary recommendation and hence the difficulty experienced by consumers to substitute goods for one another. This feature is essential to understand the full effect of sustainable diet recommendations on consumer welfare, health and the environment and hence bring some degree of realism to the analysis of sustainable diets. The second contribution of our approach is to convert the changes in diets induced by the adoption of dietary recommendations into health and environmental benefits. Thus, using an epidemiological model, on the one hand, and a dataset of environmental impacts of foods, on the other hand, it is possible to link the dietary changes simulated by the economic model to impacts on climate change and acidification indicators, and on premature mortality attributable to diet-related chronic diseases. The third contribution is to provide a framework for carrying out the benefit-cost analysis of dietary recommendations. That framework weighs the taste cost incurred by consumers against the health and environmental benefits induced by their adoption.

Our analysis presents limitations, starting with the fact that we assessed the substitutions among food categories and nutrients on the basis of consumption data, but estimated changes in diet quality from a database on individual intakes. To connect the two, we applied the percentage variations in consumption to the corresponding individual intake data. This procedure may have introduced some inaccuracies which are difficult to estimate (but also to avoid). A second limitation relates to the assumption that the consumer's utility is only a function of the quantities of the products consumed. Therefore we implicitly assumed that the consumer's utility and demand relationships were unaffected by health or environmental benefits. Even if we address this issue partially when valuing the health and environmental benefits gained from the policies, a more general framework linking explicitly nutritional and environmental recommendations to changes in consumers' preferences, and hence integrating other dimensions than price and quantity into the consumer choice problem, remains to be elaborated. Finally we have identified limitations of our study in relation to estimates of environmental impacts of foods and tried to assess the robustness of our results by considering different sets of data. Despite these limitations, we have demonstrated the practicality of the approach by investigating how food consumption, economic welfare, health and environmental outcomes would respond if French consumers adopted food-based, nutrient-based or environment-based recommendations.

The results confirm the need to consider the effects of food consumption recommendations, even if they concern only one component (sodium, SFA, added-sugar, CO2) or one food category (F\&V, meat), on the whole diet as, in most cases, they generate changes in the consumption of many food categories in a way that is difficult to predict. Looking solely at the magnitude of the environmental and health effects, a reduction in $\mathrm{CO} 2$ content of diet as well as an increase in F\&V consumption represent particularly attractive options for health and environment. Even if those measures result only in modest (5\%) changes in consumption of the targeted quantity (F\&V, CO2), they are likely to (i) prevent in excess of 2100 deaths annually, and (ii) reduce the GHGEs by 1500 to $2900 \mathrm{kt}$ of eq. CO2 per year (2000 to $3600 \mathrm{kt}$. with the second set of estimates). 
Regarding the partial cost-effectiveness analysis, the recommendation to reduce red meat consumption by $5 \%$ ranks highest for health and the two environmental indicators. The recommendations to increase by $5 \%$ the F\&V consumption and to decrease by $5 \%$ the $\mathrm{CO} 2$ content in diets are less cost-efficient because high consumers costs to comply with them. It is worthwhile to note that in most cases, the recommendations have positive impacts, even small, on both health and the environment, which confirms the possible synergies between the two domains. However, those synergies do not occur systematically, since the recommendation to decrease by $5 \%$ SFA leads to a large number of premature deaths avoided but to an increase in the carbon footprint of the diets. This is also the case for the added-sugar recommendation which has a positive impact on health but a negative one on the environmental footprint of diets.

Besides the ranking of different types of dietary recommendations, our analysis brings some additional insights for the formulation of healthy and environmentally-friendly eating policies. Hence, the large differences between shadow and actual prices that we estimated for the health-based (F\&V, sodium, SFA) and CO2 recommendations suggest that fiscal measures are unlikely to be very effective in improving dietary quality unless the tax or subsidy rates are substantial. Note however, that the gap between the shadow and actual prices is much lower for the recommendations promoting a decrease in all meats or red meat consumption (and concentrated on only these food categories). This would suggest that price policies would be more relevant in this case.

To complete the cost-benefit analysis, we estimated the maximum amount that could be invested by public authorities to promote a given recommendation so that the outcome would remain socially desirable. To compute this maximum amount, we reviewed monetary values of a statistical life (VSL) and of a Quality Adjusted Life Year (QALY) in public health literature, and social costs of $\mathrm{CO} 2$ and $\mathrm{SO} 2$ in environmental literature. Considering a range of plausible values, it turns out that: (i) informational measures focused on intakes of F\&V, SFA, sodium, and, to some extent, added-sugar, provided that they lead to at least a $5 \%$ change in the consumption of the targeted food or nutrients, would be valuable investments, given their impacts on health and/or environmental indicators; (ii) informational measures to promote a reduction of red meat or all meats consumption would be valuable investments only for high values of $\mathrm{CO} 2$ market prices (much greater than currently observed), although that result is also sensitive to the valuation of DAs. The results concerning the recommendation to decrease the $\mathrm{CO} 2$ content of diets are more ambiguous, as they depend on the LCA coefficients used in the model.

Finally, we show that the monetary values of health benefits induced by dietary recommendations are often much greater that those of environmental benefits (except for some recommendations and very high economic values of $\mathrm{CO} 2$ ). This suggests prioritizing health rather than environmental issues in information campaigns dealing with food consumption. The fact that environmental considerations have been taken into account in the formulation of dietary recommendations only very recently and partially does not appear problematic.

We conclude with a broad policy message. In recent years, the consensus about effective ways of promoting healthier and more sustainable diets has shifted, with increasing pessimism towards traditional informational measures, i.e. the formulation of dietary recommendations and their promotion via social marketing campaigns, labelling regulation and/or educational measures. Hence, Traill (2012) in his presidential address on the economics of nutrition policy evaluation concluded that "Evidence suggests that information measures (to 
perform or persuade) do not much change diets". This pessimism contrasts not only with the results of our analysis, but also the broader evidence that, at least on the health side, diet quality has in fact improved in most industrialised countries (Mazzocchi et al., 2007), even in a country such as the United States which is at the forefront of the "obesity epidemic" (Beatty et al., 2014). Further, when looking at broad trends over a long period of time, there is evidence of very large changes in dietary habits that, at least in some countries, are explained in part by the effect of public interventions. ${ }^{15}$ While recognising the difficulty of identifying the causal determinants of those trends (e.g., price and income changes versus health considerations), what might be needed is: 1- A revision of expectations regarding the effect of a short term intervention. Our analysis suggest that even a minute change in food consumption patterns can ensure cost effectiveness of a policy; and 2-A more sustained effort in promoting sustainable diet recommendations. At that level, the analysis indicates that public expenditures in the tens or hundreds of millions of Euros per year - levels that are dwarfed by expenditure on food and drinks advertising by private businesses (Matthews, 2007) - may be justified on efficiency grounds.

\section{References}

Ackerman, F., Stanton, E. (2012). Climate risks and carbon prices: revising the social cost of carbon. Economics: The Open-Access, Open-Assessment E-Journal, 6(10). http://dx.doi.org/10.5018/economics-ejournal.ja.2012-10

Althaus H, Doka G, Dones R, et al. Overview and Methodology-Datav2.0. Dübendorf, Switzerland: Ecoinvent; 2007.Anderson, H., Treich, N. (2011). The value of a statistical life. In De Palma, A., Lidsey, R., Quinet, E., Vickerman, R. edts. A Handbook of Transport Economics, Cheltenham: Edward Elgar Publishing, 2011.

Bertoluci G, Masset G, Gomy C, Mottet J, Darmon N. (2016). How to build a standardized country-specific environmental food database for nutritional epidemiology studies. Plos One. 2016; 11(4).

Beatty, T.K.M., Lin, B.-H., Smith, T.A. (2014). Is diet quality improving? Distributional changes in the United States, 1989-2008. American Journal of Agricultural Economics 96(3): 769-89.

Capacci, S., Mazzocchi, M., (201)1. Five-a-day; a price to pay: an evaluation of the UK program impact accounting for market forces. Journal of Health Economics 30, 87-98.

Carlsson-Kanyama, A., González, A.D. (2009). Potential contributions of food consumption patterns to climate change. The American Journal of Clinical Nutrition 89(5): 1704S-1709S.

Dang, T.-T., Mourougane, A. (2014). Estimating shodow prices of pollution in OECD countries. IPAG Business School Working Paper 2014-479.

Dietary Guidelines Advisory Committee - DGAC (2015). Scientific Report of the 2015 Dietary Guidelines Advisory Committee, Part A. Executive Summary. http://health.gov/dietaryguidelines/2015-scientific-report/02executive-summary.asp, consulted 30.12.2015.

\footnotetext{
15 See for instance Prättälä's presentation of the collapse in the use of butter as spread and concurrent surge in consumption of margarine and vegetables in Finland from 1978 to 2002 (Prättälä, 2003, Figure 1).
} 
Doucouliagos, C., Stanley, T.D., Giles, M. (2012). Are estimates of the value of a statistical life exaggerated? Journal of Health Economics 31: 197-206.

Drew, A.J. (2009). Government Failure and the EU ETS: What prospects for phase 3? Online publication available at: $\quad$ http://www.stockholm-network.org/downloads/publications/Andres Drew EU ETS.pdf, consulted 30.1.2015.

Ekvall, T., Assefa, G., Björklund, A., Eriksson, O., Finnveden, G. (2007). What life-cycle assessment does and does not do in assessments of waste management. Waste Management 27: 989-996.

Grunert, K. G., Shepherd, R., Traill, W. B., Wold, B. (2012). Food choice, energy balance and its determinants: Views of human behaviour in economics and psychology. Food Science \& Technology 28: 132-42.

International Standard (2006a). ISO 14040:2006 Environmental Management -Life Cycle Assessment - Principles and Framework. Geneva, Switzerland: ISO; 2006.

International Standard (2006b). ISO 14044:2006 Environmental Management -Life Cycle Assessment Requirements and Guidelines. Geneva, Switzerland: ISO; 2006.

Irz, X., Leroy, P., Requillart, V., Soler, L.-G. (2015). Economic assessment of nutritional recommendations, Journal of Health Economics, 39: 188-210.

Köster, E. P. (2007). Diversity in the determinants of food choice: A psychological perspective. Food Quality and Preferences 20: 70-82.

Macdiarmid, J.I., Kyle, J., Horgan, G.W., Loe, J., Fyfe, C., Johnstone, A., McNeill, G. (2012). Sustainable diets for the future: can we contribute to reducing greenhouse gas emissions by eating a healthy diet? The American Journal of Clinical Nutrition 96(3): 632-39.

Masset, G., Soler, L.-G., Vieux, F., Darmon, N. (2014). Identifying sustainable foods: the relationship between environmental impact, nutritional quality, and prices of foods representative of the French diet. Journal of the Academy of Nutrition and Dietetics 114(6): 862-9.

Matthews, A.E. (2007). Children and obesity: a pan-European project examining the role of food marketing. European Journal of Public Health, 18(1): 7-11.

McCabe, C., Claxton, K., Culyer, A.J. (2008). The NICE cost-effectiveness threshold. Pharmacoeconomics, 26(9): 733-744.

Mekaroonreung, M., Johnson, A.L. (2012). Estimating the shadow prices of SO2 and NOx for U.S. coal power plants: A convex nonparametric least squares approach. Energy Economics 34(3): 723-32.

Prättälä, R. (2003). Dietary changes in Finland-success stories and future challenges. Appetite 41: 245-9.

Public Health England (2015). Sugar reduction - The evidence for action. PHE publications gateway number 2015391, https://www.gov.uk/government/publications/sugar-reduction-from-evidence-into-actionconsulted online 30.12.2015. 
Scarborough, P., Nnoaham, K.E., Clarke, D., Capewell, S., Rayner, M., 2012. Modelling the impact of a healthy diet on cardiovascular disease and cancer mortality. J Epidemiol Community Health 66(5), 420-6.

Shankar, B., Brambila-Macias, J., Traill, B., Mazzocchi, M. (2013). An evaluation of the UK Food Standards Agency's salt campaign. Health Economics 22(2): 243-5.

Silva, A., Etilé, F., Jamet, G. (2013). Consequences of the 5-a-day campaign: evidence from panel data. Selected paper prepared for presentation at the Agricultural and Applied Economics Association (AAEA) Annual Meeting, Washington DC, August 4-6.

Stratham, D. (2013). Down, but not out. The New Scientist 218(2923): 26-27.

Subar, A. F., Heimendinger, J., Patterson, B. H., Krebs-Smith, S. M., Pivonka, E., Kessler, R. (1995). Fruit and vegetable intake in the United States: The baseline survey of the five a day for better health program. American Journal of Health Promotion 9(5): 352-60.

Tol, R.S.J. (2012). A cost-benefitanalysisoftheEU20/20/2020package. Energy Policy 49: 288-95.

Treich, N. (2015). La valeur de la vie humaine en économie. Futuribles 404: 63-73.

Vieux, F., Soler, L.G., Touazi, D., Darmon, N. (2013). High nutritional quality is not associated with low greenhouse gas emissions in self-selected diets of French adults. The American Journal of Clinical Nutrition, 97(3): 569-83.

Wolff, J., Orr, S. (2009). Cross-sector weighting and valuing of QALYs and VPFs - A Report for the interdepartmental group for the valuation of life and health. Available at http://www.ucl.ac.uk/cpjh/docs/IGVLH.pdf and consulted on 30.01.2015.

World Health Organization (2003). Diet, nutrition and the prevention of chronic diseases: report of a joint WHO/FAO expert consultation, Geneva, 28 January - 1 February 2002. WHO technical report series ; 916. http://www.fao.org/docrep/005/ac911e/ac911e00.HTM 


\begin{tabular}{|c|c|c|c|c|c|c|c|c|}
\hline & \multicolumn{4}{|c|}{ Men } & \multicolumn{4}{|c|}{ Women } \\
\hline & Modest & $\begin{array}{l}\text { Lower } \\
\text { average }\end{array}$ & $\begin{array}{c}\text { Upper } \\
\text { average }\end{array}$ & Well-off & Modest & $\begin{array}{l}\text { Lower } \\
\text { average }\end{array}$ & $\begin{array}{c}\text { Upper } \\
\text { average }\end{array}$ & Well-off \\
\hline \multicolumn{9}{|c|}{ DIETRON nutritional factors } \\
\hline Fruits (g) & 150 & 172 & 215 & 231 & 156 & 175 & 226 & 226 \\
\hline Vegetables (g) & 169 & 193 & 200 & 193 & 170 & 182 & 196 & 186 \\
\hline Fibers (g) & 18.4 & 19.1 & 19.8 & 20.7 & 15.1 & 15.6 & 17.1 & 16.9 \\
\hline Total Fat (\% energy) & 35.5 & 36.2 & 35.4 & 35.0 & 37.8 & 38.3 & 38.7 & 37.4 \\
\hline MUFA (\% energy) & 12.2 & 12.6 & 12.5 & 12.5 & 12.9 & 13.4 & 13.8 & 13.9 \\
\hline PUFA (\% energy) & 5.3 & 5.2 & 5.3 & 4.9 & 5.9 & 5.8 & 6.1 & 5.3 \\
\hline SFA (\% energy) & 13.8 & 14.3 & 13.6 & 13.5 & 14.8 & 14.9 & 14.5 & 14.1 \\
\hline Cholesterol (\% energy) & 0.14 & 0.14 & 0.13 & 0.14 & 0.14 & 0.14 & 0.14 & 0.14 \\
\hline Salt (g) & 8.9 & 8.7 & 8.8 & 8.9 & 6.4 & 6.5 & 6.5 & 6.4 \\
\hline Energy (MJ) & 10.2 & 10.4 & 10.5 & 10.7 & 7.7 & 7.8 & 7.9 & 7.8 \\
\hline \multicolumn{9}{|l|}{ Environmental indicators } \\
\hline eq. CO2 (g) & 4552 & 4700 & 4700 & 4773 & 3492 & 3572 & 3671 & 3739 \\
\hline eq. SO2 (g) & 60.1 & 60.7 & 58.0 & 60.6 & 43.5 & 44.4 & 44.5 & 44.8 \\
\hline
\end{tabular}

Table 1: Nutritional and environmental indicators of average daily dietary intakes, by gender and income group. 


\begin{tabular}{|c|c|c|c|c|c|c|c|c|c|c|c|c|c|c|}
\hline Lower average & \multicolumn{2}{|c|}{$\begin{array}{l}\mathrm{F} \& \mathrm{~V} \\
+5 \%\end{array}$} & \multicolumn{2}{|c|}{$\begin{array}{l}\mathrm{Na} \\
-5 \%\end{array}$} & \multicolumn{2}{|c|}{$\begin{array}{l}\text { SFA } \\
-5 \%\end{array}$} & \multicolumn{2}{|c|}{$\begin{array}{c}\text { Added sugar } \\
-5 \%\end{array}$} & \multicolumn{2}{|c|}{$\begin{array}{c}\text { eq. CO2 } \\
-5 \%\end{array}$} & \multicolumn{2}{|c|}{$\begin{array}{c}\text { Red meat } \\
-5 \%\end{array}$} & \multicolumn{2}{|c|}{$\begin{array}{c}\text { All meats } \\
-5 \%\end{array}$} \\
\hline Red meat & $0 \%$ & $-9.1 \%$ & $1 \%$ & $1.9 \%$ & $3 \%$ & $-0.3 \%$ & $0 \%$ & $5.4 \%$ & $14 \%$ & $-36.0 \%$ & $90 \%$ & $-5.5 \%$ & $23 \%$ & $-8.2 \%$ \\
\hline Other meats & $0 \%$ & $6.2 \%$ & $3 \%$ & $4.6 \%$ & $4 \%$ & $14.1 \%$ & $0 \%$ & $4.4 \%$ & $13 \%$ & $-8.7 \%$ & $0 \%$ & $0.7 \%$ & $39 \%$ & $-6.4 \%$ \\
\hline Cooked meats & $0 \%$ & $-3.3 \%$ & $19 \%$ & $-2.5 \%$ & $9 \%$ & $-3.7 \%$ & $0 \%$ & $-2.5 \%$ & $8 \%$ & $13.0 \%$ & $0 \%$ & $0.8 \%$ & $32 \%$ & $-1.3 \%$ \\
\hline All meats & $0 \%$ & $-0.3 \%$ & $23 \%$ & $1.7 \%$ & $17 \%$ & $5.2 \%$ & $1 \%$ & $2.4 \%$ & $35 \%$ & $-8.0 \%$ & $90 \%$ & $-0.7 \%$ & $94 \%$ & $-5.2 \%$ \\
\hline Milk products & $0 \%$ & $-4.3 \%$ & $7 \%$ & $3.0 \%$ & $8 \%$ & $-5.5 \%$ & $16 \%$ & $0.2 \%$ & $13 \%$ & $-7.0 \%$ & $0 \%$ & $0.7 \%$ & $0 \%$ & $3.3 \%$ \\
\hline Cheeses, butters, fresh creams & $0 \%$ & $-2.9 \%$ & $15 \%$ & $-4.0 \%$ & $44 \%$ & $-7.4 \%$ & $0 \%$ & $-4.3 \%$ & $10 \%$ & $5.4 \%$ & $0 \%$ & $0.1 \%$ & $0 \%$ & $4.2 \%$ \\
\hline Dairy pdts & $0 \%$ & $-4.0 \%$ & $21 \%$ & $1.6 \%$ & $52 \%$ & $-5.9 \%$ & $16 \%$ & $-0.7 \%$ & $23 \%$ & $-4.6 \%$ & $0 \%$ & $0.6 \%$ & $0 \%$ & $3.4 \%$ \\
\hline Fish & $0 \%$ & $9.7 \%$ & $4 \%$ & $7.6 \%$ & $1 \%$ & $8.7 \%$ & $0 \%$ & $3.6 \%$ & $4 \%$ & $30.6 \%$ & $0 \%$ & $1.7 \%$ & $0 \%$ & $7.5 \%$ \\
\hline Eggs & $0 \%$ & $-7.6 \%$ & $1 \%$ & $4.9 \%$ & $2 \%$ & $-16.0 \%$ & $0 \%$ & $-1.3 \%$ & $2 \%$ & $-16.1 \%$ & $0 \%$ & $-0.8 \%$ & $0 \%$ & $-3.3 \%$ \\
\hline Animal pdts & $0 \%$ & $-2.3 \%$ & $29 \%$ & $2.1 \%$ & $19 \%$ & $-2.4 \%$ & $1 \%$ & $0.4 \%$ & $40 \%$ & $-3.8 \%$ & $90 \%$ & $0.3 \%$ & $94 \%$ & $1.1 \%$ \\
\hline Grains & $0 \%$ & $-6.2 \%$ & $13 \%$ & $-16.5 \%$ & $1 \%$ & $-2.2 \%$ & $1 \%$ & $-0.4 \%$ & $2 \%$ & $-6.6 \%$ & $0 \%$ & $-1.0 \%$ & $0 \%$ & $-0.3 \%$ \\
\hline Potatoes & $0 \%$ & $-27.6 \%$ & $1 \%$ & $-2.8 \%$ & $1 \%$ & $2.8 \%$ & $0 \%$ & $-1.7 \%$ & $1 \%$ & $-18.1 \%$ & $0 \%$ & $-0.8 \%$ & $0 \%$ & $-4.5 \%$ \\
\hline Starchy food & $0 \%$ & $-16.1 \%$ & $15 \%$ & $-10.2 \%$ & $2 \%$ & $0.1 \%$ & $1 \%$ & $-1.0 \%$ & $3 \%$ & $-12.0 \%$ & $0 \%$ & $-0.9 \%$ & $0 \%$ & $-2.2 \%$ \\
\hline Fruits - Fresh & $41 \%$ & $-1.1 \%$ & $0 \%$ & $0.0 \%$ & $0 \%$ & $-5.0 \%$ & $0 \%$ & $0.7 \%$ & $3 \%$ & $16.5 \%$ & $0 \%$ & $1.5 \%$ & $0 \%$ & $2.7 \%$ \\
\hline Fruits - Processed & $3 \%$ & $27.0 \%$ & $0 \%$ & $2.2 \%$ & $0 \%$ & $-31.0 \%$ & $4 \%$ & $-4.7 \%$ & $0 \%$ & $20.0 \%$ & $0 \%$ & $0.2 \%$ & $0 \%$ & $-3.2 \%$ \\
\hline F\&V juices & $6 \%$ & $4.0 \%$ & $0 \%$ & $3.8 \%$ & $0 \%$ & $4.6 \%$ & $2 \%$ & $11.2 \%$ & $2 \%$ & $-0.8 \%$ & $0 \%$ & $0.8 \%$ & $0 \%$ & $-0.3 \%$ \\
\hline Vegetables - Fresh & $33 \%$ & $9.5 \%$ & $3 \%$ & $6.7 \%$ & $0 \%$ & $15.8 \%$ & $0 \%$ & $-1.4 \%$ & $4 \%$ & $2.0 \%$ & $0 \%$ & $-0.5 \%$ & $0 \%$ & $-0.3 \%$ \\
\hline Vegetables - Processed & $10 \%$ & $18.4 \%$ & $5 \%$ & $-2.9 \%$ & $0 \%$ & $10.8 \%$ & $0 \%$ & $4.5 \%$ & $2 \%$ & $-9.7 \%$ & $0 \%$ & $0.0 \%$ & $0 \%$ & $-2.7 \%$ \\
\hline Fruits - Dry & $0 \%$ & $-6.0 \%$ & $0 \%$ & $12.0 \%$ & $0 \%$ & $-5.1 \%$ & $0 \%$ & $-15.9 \%$ & $0 \%$ & $54.2 \%$ & $0 \%$ & $1.4 \%$ & $0 \%$ & $11.7 \%$ \\
\hline $\mathrm{F} \& \mathrm{~V} *$ & $93 \%$ & $5.9 \%$ & $8 \%$ & $2.3 \%$ & $1 \%$ & $3.7 \%$ & $7 \%$ & $0.1 \%$ & $11 \%$ & $8.6 \%$ & $0 \%$ & $0.5 \%$ & $0 \%$ & $0.8 \%$ \\
\hline Ready meals & $4 \%$ & $-11.7 \%$ & $9 \%$ & $-7.5 \%$ & $4 \%$ & $-5.7 \%$ & $1 \%$ & $-4.3 \%$ & $6 \%$ & $-13.0 \%$ & $10 \%$ & $-1.1 \%$ & $6 \%$ & $-3.6 \%$ \\
\hline Oil, margarine, condiments & $0 \%$ & $12.0 \%$ & $4 \%$ & $5.3 \%$ & $9 \%$ & $-2.6 \%$ & $0 \%$ & $3.5 \%$ & $1 \%$ & $-0.9 \%$ & $0 \%$ & $0.1 \%$ & $0 \%$ & $-1.2 \%$ \\
\hline Salt-fat products & $0 \%$ & $-20.7 \%$ & $7 \%$ & $-27.6 \%$ & $1 \%$ & $-28.4 \%$ & $0 \%$ & $5.8 \%$ & $1 \%$ & $18.7 \%$ & $0 \%$ & $1.2 \%$ & $0 \%$ & $10.3 \%$ \\
\hline Sugar-fat products & $3 \%$ & $2.1 \%$ & $6 \%$ & $-0.7 \%$ & $12 \%$ & $-5.9 \%$ & $57 \%$ & $-4.0 \%$ & $5 \%$ & $2.6 \%$ & $0 \%$ & $0.1 \%$ & $0 \%$ & $0.3 \%$ \\
\hline Soft drinks & $0 \%$ & $-18.4 \%$ & $0 \%$ & $-5.9 \%$ & $0 \%$ & $2.8 \%$ & $15 \%$ & $-19.2 \%$ & $1 \%$ & $28.5 \%$ & $0 \%$ & $0.7 \%$ & $0 \%$ & $5.3 \%$ \\
\hline Water & $0 \%$ & $-20.0 \%$ & $1 \%$ & $1.6 \%$ & $0 \%$ & $9.7 \%$ & $0 \%$ & $6.3 \%$ & $3 \%$ & $-4.8 \%$ & $0 \%$ & $1.8 \%$ & $0 \%$ & $10.0 \%$ \\
\hline Alcoholic beverages & $0 \%$ & $12.9 \%$ & $0 \%$ & $1.3 \%$ & $0 \%$ & $4.8 \%$ & $2 \%$ & $1.9 \%$ & $5 \%$ & $-1.1 \%$ & $0 \%$ & $0.3 \%$ & $0 \%$ & $-0.4 \%$ \\
\hline
\end{tabular}

* Except $\mathrm{F} \& \mathrm{~V}$ juices

Table 2: Changes in food consumption induced by the imposition of dietary constraints (percentage on the right in each column) \& baseline contribution of each food group to the constrained quantity (percentage on the left in each column) for the "Lower-average" consumer type. 


\begin{tabular}{|l|r|r|r|r|r|r|r|}
\cline { 2 - 7 } \multicolumn{1}{c|}{ Lower average } & \multicolumn{1}{c|}{$\begin{array}{c}\mathrm{F} \& \mathrm{~V} \\
+5 \%\end{array}$} & \multicolumn{1}{c|}{$\mathrm{Na}$} & \multicolumn{1}{c|}{ SFA } & \multicolumn{1}{c|}{$\begin{array}{c}\text { Added } \\
\text { seq. CO2 }\end{array}$} & $\begin{array}{c}\text { Red meat } \\
\text { sugar }\end{array}$ & $\begin{array}{c}\text { All meats } \\
-5 \%\end{array}$ & $\begin{array}{c}-5 \% \\
-5 \%\end{array}$ \\
\hline Red meat & $0.0 \%$ & $0.8 \%$ & $5.5 \%$ & $0.0 \%$ & $82.1 \%$ & $3.8 \%$ & $9.8 \%$ \\
Other meats & $0.0 \%$ & $1.2 \%$ & $5.7 \%$ & $0.1 \%$ & $61.4 \%$ & $0.0 \%$ & $13.3 \%$ \\
Cooked meats & $0.0 \%$ & $8.6 \%$ & $10.9 \%$ & $0.2 \%$ & $34.9 \%$ & $0.0 \%$ & $10.6 \%$ \\
Fish & $0.0 \%$ & $2.6 \%$ & $1.4 \%$ & $0.0 \%$ & $25.9 \%$ & $0.0 \%$ & $0.0 \%$ \\
Eggs & $0.0 \%$ & $5.0 \%$ & $20.4 \%$ & $0.5 \%$ & $66.0 \%$ & $0.0 \%$ & $0.0 \%$ \\
Grains & $-0.4 \%$ & $23.1 \%$ & $3.4 \%$ & $2.3 \%$ & $39.4 \%$ & $0.0 \%$ & $0.0 \%$ \\
Potatoes & $0.0 \%$ & $5.5 \%$ & $19.5 \%$ & $0.0 \%$ & $54.9 \%$ & $0.0 \%$ & $0.0 \%$ \\
Fruits - fresh & $-34.7 \%$ & $0.1 \%$ & $0.3 \%$ & $0.2 \%$ & $23.6 \%$ & $0.0 \%$ & $0.0 \%$ \\
Fruits - processed & $-24.4 \%$ & $0.1 \%$ & $0.1 \%$ & $33.8 \%$ & $25.5 \%$ & $0.0 \%$ & $0.0 \%$ \\
F\&V juices & $-16.5 \%$ & $0.3 \%$ & $0.4 \%$ & $5.9 \%$ & $45.4 \%$ & $0.0 \%$ & $0.0 \%$ \\
Vegetables - fresh & $-34.0 \%$ & $3.0 \%$ & $1.0 \%$ & $0.0 \%$ & $34.7 \%$ & $0.0 \%$ & $0.0 \%$ \\
Vegetables - processed & $-22.7 \%$ & $9.9 \%$ & $1.0 \%$ & $0.4 \%$ & $45.1 \%$ & $0.0 \%$ & $0.0 \%$ \\
Fruits - dry & $-6.5 \%$ & $0.9 \%$ & $6.1 \%$ & $0.2 \%$ & $11.0 \%$ & $0.0 \%$ & $0.0 \%$ \\
Milk products & $0.0 \%$ & $3.1 \%$ & $10.8 \%$ & $7.6 \%$ & $59.9 \%$ & $0.0 \%$ & $0.0 \%$ \\
Cheeses, butters, fresh creams & $0.0 \%$ & $6.6 \%$ & $54.4 \%$ & $0.0 \%$ & $44.6 \%$ & $0.0 \%$ & $0.0 \%$ \\
Ready meals & $-3.3 \%$ & $6.6 \%$ & $7.1 \%$ & $0.4 \%$ & $42.1 \%$ & $0.5 \%$ & $3.3 \%$ \\
Oil, margarine, condiments & $0.0 \%$ & $11.0 \%$ & $64.2 \%$ & $0.0 \%$ & $35.9 \%$ & $0.0 \%$ & $0.0 \%$ \\
Salt-fat products & $0.0 \%$ & $28.7 \%$ & $10.8 \%$ & $1.1 \%$ & $30.1 \%$ & $0.0 \%$ & $0.2 \%$ \\
Sugar-fat products & $-1.4 \%$ & $2.3 \%$ & $13.9 \%$ & $24.6 \%$ & $22.4 \%$ & $0.0 \%$ & $0.0 \%$ \\
Soft drinks & $0.0 \%$ & $0.5 \%$ & $0.6 \%$ & $41.5 \%$ & $25.5 \%$ & $0.0 \%$ & $0.0 \%$ \\
Water & $0.0 \%$ & $1.4 \%$ & $0.0 \%$ & $0.0 \%$ & $55.8 \%$ & $0.0 \%$ & $0.0 \%$ \\
Alcoholic beverages & $0.0 \%$ & $0.1 \%$ & $0.0 \%$ & $1.0 \%$ & $23.4 \%$ & $0.0 \%$ & $0.0 \%$ \\
\hline
\end{tabular}

Table 3: Relative difference between shadow and actual prices of each food group for each dietary constraint ("Lower-average" consumer type). 


\begin{tabular}{|c|c|c|c|c|c|c|c|}
\hline & $\begin{array}{l}\mathrm{F} \& \mathrm{~V} \\
+5 \% \\
\end{array}$ & $\begin{array}{l}\mathrm{Na} \\
-5 \% \\
\end{array}$ & $\begin{array}{l}\text { SFA } \\
-5 \% \\
\end{array}$ & $\begin{array}{c}\text { Added sugar } \\
-5 \% \\
\end{array}$ & $\begin{array}{c}\text { eq. } \mathrm{CO} 2 \\
-5 \% \\
\end{array}$ & $\begin{array}{c}\text { Red meat } \\
-5 \% \\
\end{array}$ & $\begin{array}{c}\text { All meats } \\
-5 \% \\
\end{array}$ \\
\hline $\begin{array}{c}\text { Consumers cost (M€) } \\
\% \text { food budget }\end{array}$ & $\begin{array}{c}466 \\
0.64 \%\end{array}$ & $\begin{array}{c}128 \\
0.17 \%\end{array}$ & $\begin{array}{c}288 \\
0.37 \%\end{array}$ & $\begin{array}{c}152 \\
0.20 \%\end{array}$ & $\begin{array}{c}961 \\
1.25 \%\end{array}$ & $\begin{array}{c}10 \\
0.01 \%\end{array}$ & $\begin{array}{c}76 \\
0.10 \%\end{array}$ \\
\hline $\begin{array}{c}\text { DA } \\
\text { (95\% confidence interval) } \\
\text { \% DA for DIETRON diseases }\end{array}$ & $\begin{array}{c}2507 \\
(2174,2844) \\
3.8 \%\end{array}$ & $\begin{array}{c}2852 \\
(2424,3293) \\
4.3 \%\end{array}$ & $\begin{array}{c}2140 \\
(1761,2514) \\
3.2 \%\end{array}$ & $\begin{array}{c}941 \\
(802,1085) \\
1.4 \%\end{array}$ & $\begin{array}{c}2331 \\
(1959,2695) \\
3.5 \%\end{array}$ & $\begin{array}{c}230 \\
(192,267) \\
0.3 \%\end{array}$ & $\begin{array}{c}245 \\
(183,308) \\
0.4 \%\end{array}$ \\
\hline $\begin{array}{l}\text { Consumers cost per DA (K€) } \\
(95 \% \text { confidence interval) }\end{array}$ & $\begin{array}{c}186 \\
(164,214) \\
\end{array}$ & $\begin{array}{c}45 \\
(39,53) \\
\end{array}$ & $\begin{array}{c}135 \\
(115,164) \\
\end{array}$ & $\begin{array}{c}162 \\
(140,190) \\
\end{array}$ & $\begin{array}{c}412 \\
(357,491) \\
\end{array}$ & $\begin{array}{c}45 \\
(39,54) \\
\end{array}$ & $\begin{array}{c}311 \\
(248,418) \\
\end{array}$ \\
\hline $\begin{array}{c}\Delta \text { eq. CO2 }(\mathrm{Kt}) \\
(95 \% \text { confidence interval })\end{array}$ & $\begin{array}{c}-1574 \\
(-1861,-1310)\end{array}$ & $\begin{array}{c}-460 \\
(-600,-324)\end{array}$ & $\begin{array}{c}259 \\
(71,469)\end{array}$ & $\begin{array}{c}336 \\
(163,537)\end{array}$ & $\begin{array}{c}-2985 \\
(-3857,-2303)\end{array}$ & $\begin{array}{c}-274 \\
(-396,-181)\end{array}$ & $\begin{array}{c}-513 \\
(-747,-322)\end{array}$ \\
\hline $\begin{array}{l}\text { Consumers cost to decrease eq. CO2 (€/t) } \\
(95 \% \text { confidence interval })\end{array}$ & $\begin{array}{c}296 \\
(250,356) \\
\end{array}$ & $\begin{array}{c}279 \\
(213,395) \\
\end{array}$ & & & $\begin{array}{c}322 \\
(249,417) \\
\end{array}$ & $\begin{array}{c}38 \\
(26,57) \\
\end{array}$ & $\begin{array}{c}149 \\
(102,237)\end{array}$ \\
\hline $\begin{array}{c}\Delta \text { eq. SO2 }(\mathrm{Kt}) \\
(95 \% \text { confidence interval) }\end{array}$ & $\begin{array}{c}-27 \\
(-32,-23)\end{array}$ & $\begin{array}{c}-4 \\
(-6,-2)\end{array}$ & $\begin{array}{c}-3 \\
(-6,0)\end{array}$ & $\begin{array}{c}4 \\
(1,8)\end{array}$ & $\begin{array}{c}-67 \\
(-85,-53)\end{array}$ & $\begin{array}{c}-7 \\
(-10,-5)\end{array}$ & $\begin{array}{c}-17 \\
(-22,-14)\end{array}$ \\
\hline $\begin{array}{l}\text { Consumers cost to decrease eq. SO2 }(€ / t) \\
(95 \% \text { confidence interval })\end{array}$ & $\begin{array}{c}17100 \\
(14474,20158)\end{array}$ & $\begin{array}{c}32417 \\
(22288,61380)\end{array}$ & $\begin{array}{c}104985 \\
(51939,-670485)\end{array}$ & & $\begin{array}{c}14347 \\
(11269,18135)\end{array}$ & $\begin{array}{c}1442 \\
(1063,1976)\end{array}$ & $\begin{array}{c}4376 \\
(3433,5581)\end{array}$ \\
\hline
\end{tabular}

Table 4: Comparison of the constraints in terms of consumers cost, effects on health and the environment, and partial efficiency

\begin{tabular}{|l|r|r|r|r|r|r|r|}
\cline { 2 - 7 } \multicolumn{1}{c|}{} & \begin{tabular}{c} 
F\&V \\
\multicolumn{1}{c|}{} \\
\multicolumn{1}{c|}{$+5 \%$}
\end{tabular} & \begin{tabular}{c} 
Na \\
\multicolumn{1}{c|}{$-5 \%$}
\end{tabular} & \begin{tabular}{c} 
SFA \\
\multicolumn{1}{c|}{$-5 \%$}
\end{tabular} & $\begin{array}{c}\text { Added } \\
\text { sugar }\end{array}$ & $\begin{array}{c}\text { eq. CO2 } \\
-5 \%\end{array}$ & $\begin{array}{c}\text { Red meat } \\
-5 \%\end{array}$ & $\begin{array}{c}\text { All meats } \\
-5 \%\end{array}$ \\
\hline DIETRON nutritional factors & & & & & & & \\
Fruits (g) & $1.7 \%$ & $0.5 \%$ & $-5.4 \%$ & $0.9 \%$ & $14.0 \%$ & $1.1 \%$ & $1.8 \%$ \\
Vegetables (g) & $7.0 \%$ & $2.6 \%$ & $10.8 \%$ & $-1.1 \%$ & $-2.6 \%$ & $-0.5 \%$ & $-1.3 \%$ \\
Fibers (g) & $-2.3 \%$ & $-5.0 \%$ & $-0.2 \%$ & $-1.3 \%$ & $-0.9 \%$ & $-0.2 \%$ & $-0.3 \%$ \\
Total Fat (\% energy) & $1.4 \%$ & $2.7 \%$ & $-1.0 \%$ & $-0.1 \%$ & $1.2 \%$ & $0.1 \%$ & $0.1 \%$ \\
MUFA (\% energy) & $2.6 \%$ & $3.6 \%$ & $-0.4 \%$ & $0.6 \%$ & $0.9 \%$ & $0.1 \%$ & $-0.3 \%$ \\
PUFA (\% energy) & $4.7 \%$ & $3.8 \%$ & $0.0 \%$ & $1.8 \%$ & $2.8 \%$ & $0.2 \%$ & $-0.1 \%$ \\
SFA (\% energy) & $-0.4 \%$ & $1.6 \%$ & $-2.3 \%$ & $-1.6 \%$ & $1.5 \%$ & $0.1 \%$ & $0.9 \%$ \\
Cholesterol (\% energy) & $-0.8 \%$ & $3.7 \%$ & $-1.5 \%$ & $-0.3 \%$ & $-2.0 \%$ & $-0.1 \%$ & $-1.0 \%$ \\
Salt (g) & $-5.1 \%$ & $-7.7 \%$ & $-3.9 \%$ & $-1.2 \%$ & $-0.9 \%$ & $-0.2 \%$ & $0.3 \%$ \\
Energy (MJ) & $-2.3 \%$ & $-3.8 \%$ & $-2.5 \%$ & $-1.3 \%$ & $-1.8 \%$ & $-0.2 \%$ & $-0.3 \%$ \\
\hline Environmental indicators & & & & & & & \\
eq. CO2 (g) & $-2.8 \%$ & $-0.8 \%$ & $0.5 \%$ & $0.6 \%$ & $-5.3 \%$ & $-0.5 \%$ & $-0.9 \%$ \\
eq. SO2 (g) & $-3.9 \%$ & $-0.6 \%$ & $-0.4 \%$ & $0.6 \%$ & $-9.5 \%$ & $-1.0 \%$ & $-2.5 \%$ \\
\hline
\end{tabular}

Table 5: Population average variations in nutritional and environmental indicators and in death avoided 


\begin{tabular}{|c|c|c|c|c|c|c|c|c|c|}
\hline Valuation Parameters & & & & & & & & & \\
\hline $\mathrm{DA}(\mathrm{K} € / \mathrm{DA})$ & 240 & 240 & 1000 & 1000 & & 240 & 240 & 1000 & 1000 \\
\hline eq. $\mathrm{CO} 2(€ / t)$ & 32 & 185 & 32 & 185 & & 32 & 185 & 32 & 185 \\
\hline eq. SO2 (€/t) & 238 & 238 & 238 & 238 & & 238 & 238 & 238 & 238 \\
\hline Constraints & \multicolumn{4}{|c|}{ Benefits (M€) } & Cost (M€) & \multicolumn{4}{|c|}{$\mathrm{C}_{\mathrm{p}}$ Max Campaign (M€) } \\
\hline $\begin{array}{l}\mathrm{F} \& \mathrm{~V}+5 \% \\
\text { (95\% confidence interval) }\end{array}$ & $\begin{array}{c}659 \\
(578,740)\end{array}$ & $\begin{array}{c}900 \\
(807,996)\end{array}$ & $\begin{array}{c}2564 \\
(2231,2901) \\
\end{array}$ & $\begin{array}{c}2805 \\
(2470,3146) \\
\end{array}$ & 466 & $\begin{array}{c}193 \\
(112,274)\end{array}$ & $\begin{array}{c}433 \\
(341,530)\end{array}$ & $\begin{array}{c}2098 \\
(1765,2435)\end{array}$ & $\begin{array}{c}2339 \\
(2004,2680) \\
\end{array}$ \\
\hline $\begin{array}{l}\mathrm{Na}-5 \% \\
\text { (idem) }\end{array}$ & $\begin{array}{c}700 \\
(598,806) \\
\end{array}$ & $\begin{array}{c}771 \\
(667,877) \\
\end{array}$ & $\begin{array}{c}2867 \\
(2440,3309) \\
\end{array}$ & $\begin{array}{c}2938 \\
(2512,3378) \\
\end{array}$ & 128 & $\begin{array}{c}572 \\
(470,678) \\
\end{array}$ & $\begin{array}{c}642 \\
(539,749) \\
\end{array}$ & $\begin{array}{c}2739 \\
(2312,3180) \\
\end{array}$ & $\begin{array}{c}2810 \\
(2384,3250) \\
\end{array}$ \\
\hline $\begin{array}{c}\text { SFA -5\% } \\
\text { (idem) } \\
\end{array}$ & $\begin{array}{c}506 \\
(417,594) \\
\end{array}$ & $\begin{array}{c}466 \\
(378,553) \\
\end{array}$ & $\begin{array}{c}2133 \\
(1755,2504) \\
\end{array}$ & $\begin{array}{c}2092 \\
(1722,2457) \\
\end{array}$ & 288 & $\begin{array}{c}217 \\
(128,305) \\
\end{array}$ & $\begin{array}{c}177 \\
(89,265) \\
\end{array}$ & $\begin{array}{c}1844 \\
(1466,2215) \\
\end{array}$ & $\begin{array}{c}1804 \\
(1433,2169) \\
\end{array}$ \\
\hline $\begin{array}{c}\text { Added sugar }-5 \% \\
\text { (idem) }\end{array}$ & $\begin{array}{c}214 \\
(180,249) \\
\end{array}$ & $\begin{array}{c}162 \\
(114,209) \\
\end{array}$ & $\begin{array}{c}929 \\
(790,1073) \\
\end{array}$ & $\begin{array}{c}877 \\
(736,1023) \\
\end{array}$ & 152 & $\begin{array}{c}62 \\
(28,97) \\
\end{array}$ & $\begin{array}{c}10 \\
(-38,57) \\
\end{array}$ & $\begin{array}{c}777 \\
(638,921) \\
\end{array}$ & $\begin{array}{c}725 \\
(584,871) \\
\end{array}$ \\
\hline $\begin{array}{r}\text { eq. } \mathrm{CO} 2-5 \% \\
\text { (idem) }\end{array}$ & $\begin{array}{c}672 \\
(577,765) \\
\end{array}$ & $\begin{array}{c}1128 \\
(968,1318)\end{array}$ & $\begin{array}{c}2444 \\
(2070,2810) \\
\end{array}$ & $\begin{array}{c}2903 \\
(2502,3305) \\
\end{array}$ & 961 & $\begin{array}{c}-290 \\
(-384,-196)\end{array}$ & $\begin{array}{c}167 \\
(6,356)\end{array}$ & $\begin{array}{c}1482 \\
(1108,1848)\end{array}$ & $\begin{array}{c}1942 \\
(1541,2343)\end{array}$ \\
\hline $\begin{array}{r}\text { Red meat }-5 \% \\
\text { (idem) }\end{array}$ & $\begin{array}{c}66 \\
(56,76)\end{array}$ & $\begin{array}{c}108 \\
(87,133)\end{array}$ & $\begin{array}{c}240 \\
(202,279)\end{array}$ & $\begin{array}{c}283 \\
(239,328)\end{array}$ & 10 & $\begin{array}{c}55 \\
(45,66)\end{array}$ & $\begin{array}{c}97 \\
(76,123)\end{array}$ & $\begin{array}{c}230 \\
(192,268)\end{array}$ & $\begin{array}{c}272 \\
(228,318)\end{array}$ \\
\hline $\begin{array}{r}\text { All meats -5\% } \\
\text { (idem) }\end{array}$ & $\begin{array}{c}80 \\
(63,97)\end{array}$ & $\begin{array}{c}158 \\
(119,205)\end{array}$ & $\begin{array}{c}266 \\
(203,330)\end{array}$ & $\begin{array}{c}345 \\
(272,422)\end{array}$ & 76 & $\begin{array}{c}3 \\
(-13,21)\end{array}$ & $\begin{array}{c}82 \\
(43,129)\end{array}$ & $\begin{array}{c}190 \\
(127,253)\end{array}$ & $\begin{array}{c}269 \\
(196,346)\end{array}$ \\
\hline
\end{tabular}

Table 6: Cost-effectiveness analysis

\begin{tabular}{|c|cccc|}
\cline { 1 - 4 } Valuation Parameters & \multicolumn{4}{|c|}{} \\
DA (K€/DA) & 240 & 240 & 1000 & 1000 \\
eq. CO2 $(€ / t)$ & 32 & 185 & 32 & 185 \\
eq. SO2 $(€ / t)$ & 238 & 238 & 238 & 238 \\
\hline Constraints & \multicolumn{4}{|c}{ Share of health benefit in total benefit } \\
\hline F\&V +5\% & $91 \%$ & $67 \%$ & $98 \%$ & $89 \%$ \\
(95\% confidence interval) & $(89 \%, 93 \%)$ & $(62 \%, 72 \%)$ & $(97 \%, 98 \%)$ & $(87 \%, 91 \%)$ \\
\hline Na -5\% & $98 \%$ & $89 \%$ & $99 \%$ & $97 \%$ \\
(idem) & $(97 \%, 98 \%)$ & $(85 \%, 92 \%)$ & $(99 \%, 100 \%)$ & $(96 \%, 98 \%)$ \\
\hline SFA -5\% & $102 \%$ & $110 \%$ & $100 \%$ & $102 \%$ \\
(idem) & $(100 \%, 103 \%)$ & $(102 \%, 120 \%)$ & $(100 \%, 101 \%)$ & $(101 \%, 104 \%)$ \\
\hline Added sugar -5\% & $106 \%$ & $139 \%$ & $101 \%$ & $107 \%$ \\
(idem) & $(102 \%, 109 \%)$ & $(115 \%, 184 \%)$ & $(101 \%, 102 \%)$ & $(103 \%, 112 \%)$ \\
\hline eq. CO2 -5\% & $83 \%$ & $50 \%$ & $95 \%$ & $80 \%$ \\
(idem) & $(79 \%, 87 \%)$ & $(42 \%, 57 \%)$ & $(94 \%, 97 \%)$ & $(75 \%, 85 \%)$ \\
\hline Red meat -5\% & $84 \%$ & $51 \%$ & $96 \%$ & $81 \%$ \\
(idem) & $(78 \%, 89 \%)$ & $(42 \%, 62 \%)$ & $(94 \%, 97 \%)$ & $(75 \%, 87 \%)$ \\
\hline All meats -5\% & $74 \%$ & $37 \%$ & $92 \%$ & $71 \%$ \\
(idem) & $(65 \%, 82 \%)$ & $(27 \%, 50 \%)$ & $(88 \%, 95 \%)$ & $(61 \%, 81 \%)$ \\
\hline
\end{tabular}

Table 7: Shares of total benefit attributable to health versus environmental improvements 


\begin{tabular}{|c|c|c|c|c|c|c|c|c|}
\cline { 3 - 10 } \multicolumn{2}{c|}{} & $\begin{array}{c}\text { F\&V } \\
+5 \%\end{array}$ & $\begin{array}{c}\text { Na } \\
-5 \%\end{array}$ & $\begin{array}{c}\text { SFA } \\
-5 \%\end{array}$ & Added sugar & eq. CO2 & Red meat & All meats \\
\hline \multirow{3}{*}{$\Delta$ eq. CO2 (Kt) } & COEFF 1 & -1574 & -460 & 259 & 336 & $-5 \%$ & $-5 \%$ & $-5 \%$ \\
\cline { 2 - 11 } & COEFF 2 & -2081 & -576 & -263 & 532 & -3656 & -274 & -513 \\
\hline
\end{tabular}

Table 8. Variations of GHG emissions induced by the adoption of the dietary constraints for the two sets of coefficients used (COEFF 1: initial LCA coefficients of food groups; COEFF 2: LCA coefficients of food groups based on the literature review by Bertoluci et al. 2016)

\begin{tabular}{|c|c|c|c|c|c|c|}
\hline & \multicolumn{2}{|c|}{ Total Benefit } & \multicolumn{2}{|c|}{ Max campaign } & \multicolumn{2}{|c|}{$\begin{array}{l}\text { Shares of total benefit } \\
\text { attributable to health } \\
\text { versus environmental } \\
\text { improvements }\end{array}$} \\
\hline & COEFF 1 & COEFF 2 & COEFF 1 & COEFF 2 & COEFF 1 & COEFF 2 \\
\hline $\mathrm{F} \& \mathrm{~V}+5 \%$ & 659 & 675 & 193 & 209 & $91 \%$ & $89 \%$ \\
\hline $\mathrm{Na}-5 \%$ & 700 & 704 & 572 & 576 & $98 \%$ & $97 \%$ \\
\hline SFA -5\% & 506 & 523 & 217 & 234 & $102 \%$ & $98 \%$ \\
\hline Added sugar -5\% & 214 & 207 & 62 & 55 & $106 \%$ & $109 \%$ \\
\hline eq. CO2 -5\% & 672 & 533 & -290 & 73 & $83 \%$ & $76 \%$ \\
\hline Red meat -5\% & 66 & 74 & 55 & 63 & $84 \%$ & $75 \%$ \\
\hline All meats $-5 \%$ & 80 & 86 & 3 & 9 & $74 \%$ & $69 \%$ \\
\hline
\end{tabular}

(Parameters: DA: $240 \mathrm{~K} € / \mathrm{DA}$; eq. CO2: 32€/t; eq. SO2: 238€/t)

Table 9. Cost-effectiveness of dietary recommendations (COEFF 1: initial LCA coefficients of food groups; COEFF 2: LCA coefficients of food groups based on the literature review by Bertoluci et al. 2016) 


\section{Appendix A:}

\begin{tabular}{|c|c|c|c|c|c|c|c|c|c|c|c|c|c|c|}
\hline Modest & \multicolumn{2}{|c|}{$\begin{array}{r}\mathrm{F} \& \mathrm{~V} \\
+5 \% \\
\end{array}$} & \multicolumn{2}{|c|}{$\begin{array}{l}\mathrm{Na} \\
-5 \% \\
\end{array}$} & \multicolumn{2}{|c|}{$\begin{array}{l}\text { SFA } \\
-5 \% \\
\end{array}$} & \multicolumn{2}{|c|}{$\begin{array}{c}\text { Added sugar } \\
-5 \% \\
\end{array}$} & \multicolumn{2}{|c|}{$\begin{array}{c}\text { eq. } \mathrm{CO} 2 \\
-5 \% \\
\end{array}$} & \multicolumn{2}{|c|}{$\begin{array}{c}\text { Red meat } \\
-5 \% \\
\end{array}$} & \multicolumn{2}{|c|}{$\begin{array}{c}\text { All meats } \\
-5 \%\end{array}$} \\
\hline Red meat & $0 \%$ & $-17.3 \%$ & $1 \%$ & $1.9 \%$ & $3 \%$ & $-0.4 \%$ & $0 \%$ & $4.8 \%$ & $13 \%$ & $-38.4 \%$ & $88 \%$ & $-5.6 \%$ & $21 \%$ & $-8.6 \%$ \\
\hline Other meats & $0 \%$ & $13.0 \%$ & $2 \%$ & $4.9 \%$ & $4 \%$ & $14.5 \%$ & $0 \%$ & $4.0 \%$ & $12 \%$ & $-8.7 \%$ & $0 \%$ & $0.7 \%$ & $38 \%$ & $-6.4 \%$ \\
\hline Cooked meats & $0 \%$ & $-6.5 \%$ & $18 \%$ & $-2.2 \%$ & $8 \%$ & $-3.1 \%$ & $0 \%$ & $-1.7 \%$ & $8 \%$ & $13.4 \%$ & $0 \%$ & $0.8 \%$ & $34 \%$ & $-1.4 \%$ \\
\hline All meats & $0 \%$ & $-0.1 \%$ & $22 \%$ & $1.8 \%$ & $15 \%$ & $5.4 \%$ & $1 \%$ & $2.3 \%$ & $33 \%$ & $-7.7 \%$ & $88 \%$ & $-0.6 \%$ & $93 \%$ & $-5.2 \%$ \\
\hline Milk products & $0 \%$ & $-8.1 \%$ & $7 \%$ & $2.9 \%$ & $9 \%$ & $-4.4 \%$ & $15 \%$ & $0.3 \%$ & $14 \%$ & $-8.0 \%$ & $0 \%$ & $0.6 \%$ & $0 \%$ & $3.1 \%$ \\
\hline Cheeses, butters, fresh creams & $0 \%$ & $-5.5 \%$ & $15 \%$ & $-3.7 \%$ & $43 \%$ & $-7.4 \%$ & $0 \%$ & $-2.9 \%$ & $10 \%$ & $5.3 \%$ & $0 \%$ & $0.1 \%$ & $0 \%$ & $4.1 \%$ \\
\hline Dairy pdts & $0 \%$ & $-7.6 \%$ & $21 \%$ & $1.7 \%$ & $52 \%$ & $-5.0 \%$ & $15 \%$ & $-0.3 \%$ & $24 \%$ & $-5.5 \%$ & $0 \%$ & $0.5 \%$ & $0 \%$ & $3.3 \%$ \\
\hline Fish & $0 \%$ & $24.0 \%$ & $3 \%$ & $8.4 \%$ & $1 \%$ & $8.7 \%$ & $0 \%$ & $3.3 \%$ & $3 \%$ & $34.2 \%$ & $0 \%$ & $1.7 \%$ & $0 \%$ & $7.9 \%$ \\
\hline Eggs & $0 \%$ & $-14.2 \%$ & $1 \%$ & $4.9 \%$ & $2 \%$ & $-14.8 \%$ & $0 \%$ & $-0.6 \%$ & $2 \%$ & $-16.9 \%$ & $0 \%$ & $-0.8 \%$ & $0 \%$ & $-3.3 \%$ \\
\hline Animal pdts & $0 \%$ & $-4.3 \%$ & $27 \%$ & $2.2 \%$ & $18 \%$ & $-2.0 \%$ & $1 \%$ & $0.5 \%$ & $38 \%$ & $-4.4 \%$ & $88 \%$ & $0.2 \%$ & $93 \%$ & $1.2 \%$ \\
\hline Grains & $0 \%$ & $-11.1 \%$ & $15 \%$ & $-16.1 \%$ & $1 \%$ & $-0.6 \%$ & $1 \%$ & $0.3 \%$ & $3 \%$ & $-6.2 \%$ & $0 \%$ & $-0.8 \%$ & $0 \%$ & $0.0 \%$ \\
\hline Potatoes & $0 \%$ & $-46.7 \%$ & $1 \%$ & $-2.6 \%$ & $1 \%$ & $3.3 \%$ & $0 \%$ & $-1.2 \%$ & $1 \%$ & $-18.9 \%$ & $0 \%$ & $-0.8 \%$ & $0 \%$ & $-4.7 \%$ \\
\hline Starchy food & $0 \%$ & $-26.8 \%$ & $16 \%$ & $-10.1 \%$ & $2 \%$ & $1.1 \%$ & $1 \%$ & $-0.4 \%$ & $4 \%$ & $-11.8 \%$ & $0 \%$ & $-0.8 \%$ & $0 \%$ & $-2.1 \%$ \\
\hline Fruits - Fresh & $40 \%$ & $-6.8 \%$ & $0 \%$ & $0.0 \%$ & $0 \%$ & $-5.3 \%$ & $0 \%$ & $0.8 \%$ & $3 \%$ & $17.4 \%$ & $0 \%$ & $1.5 \%$ & $0 \%$ & $2.6 \%$ \\
\hline Fruits - Processed & $3 \%$ & $51.2 \%$ & $0 \%$ & $2.4 \%$ & $0 \%$ & $-29.0 \%$ & $4 \%$ & $-3.9 \%$ & $0 \%$ & $20.5 \%$ & $0 \%$ & $0.1 \%$ & $0 \%$ & $-3.3 \%$ \\
\hline F\&V juices & $7 \%$ & $4.6 \%$ & $0 \%$ & $4.0 \%$ & $0 \%$ & $4.7 \%$ & $2 \%$ & $9.6 \%$ & $2 \%$ & $-0.9 \%$ & $0 \%$ & $0.8 \%$ & $0 \%$ & $-0.4 \%$ \\
\hline Vegetables - Fresh & $31 \%$ & $10.6 \%$ & $3 \%$ & $7.7 \%$ & $0 \%$ & $16.3 \%$ & $0 \%$ & $-1.3 \%$ & $3 \%$ & $2.0 \%$ & $0 \%$ & $-0.6 \%$ & $0 \%$ & $-0.9 \%$ \\
\hline Vegetables - Processed & $11 \%$ & $33.1 \%$ & $5 \%$ & $-3.0 \%$ & $0 \%$ & $10.6 \%$ & $0 \%$ & $4.0 \%$ & $2 \%$ & $-9.7 \%$ & $0 \%$ & $0.0 \%$ & $0 \%$ & $-2.3 \%$ \\
\hline Fruits - Dry & $0 \%$ & $-12.0 \%$ & $0 \%$ & $12.4 \%$ & $0 \%$ & $-4.6 \%$ & $0 \%$ & $-13.3 \%$ & $0 \%$ & $58.9 \%$ & $0 \%$ & $1.4 \%$ & $0 \%$ & $12.0 \%$ \\
\hline $\mathrm{F} \& \mathrm{~V} *$ & $92 \%$ & $6.4 \%$ & $8 \%$ & $2.5 \%$ & $1 \%$ & $3.8 \%$ & $6 \%$ & $0.2 \%$ & $11 \%$ & $8.7 \%$ & $0 \%$ & $0.5 \%$ & $0 \%$ & $0.6 \%$ \\
\hline Ready meals & $5 \%$ & $-21.6 \%$ & $10 \%$ & $-7.0 \%$ & $4 \%$ & $-4.5 \%$ & $1 \%$ & $-2.8 \%$ & $6 \%$ & $-13.0 \%$ & $12 \%$ & $-1.0 \%$ & $7 \%$ & $-3.6 \%$ \\
\hline Oil, margarine, condiments & $0 \%$ & $19.4 \%$ & $4 \%$ & $4.2 \%$ & $9 \%$ & $-5.6 \%$ & $0 \%$ & $3.3 \%$ & $2 \%$ & $-0.7 \%$ & $0 \%$ & $0.1 \%$ & $0 \%$ & $-0.9 \%$ \\
\hline Salt-fat products & $0 \%$ & $-33.0 \%$ & $7 \%$ & $-26.5 \%$ & $1 \%$ & $-25.0 \%$ & $0 \%$ & $4.9 \%$ & $1 \%$ & $18.4 \%$ & $0 \%$ & $1.1 \%$ & $0 \%$ & $9.6 \%$ \\
\hline Sugar-fat products & $3 \%$ & $2.2 \%$ & $6 \%$ & $-0.3 \%$ & $13 \%$ & $-4.9 \%$ & $58 \%$ & $-4.1 \%$ & $6 \%$ & $3.8 \%$ & $0 \%$ & $0.1 \%$ & $0 \%$ & $0.5 \%$ \\
\hline Soft drinks & $0 \%$ & $-28.0 \%$ & $0 \%$ & $-4.0 \%$ & $0 \%$ & $4.1 \%$ & $16 \%$ & $-17.1 \%$ & $1 \%$ & $26.2 \%$ & $0 \%$ & $0.6 \%$ & $0 \%$ & $4.8 \%$ \\
\hline Water & $0 \%$ & $-36.1 \%$ & $1 \%$ & $1.6 \%$ & $0 \%$ & $9.5 \%$ & $0 \%$ & $5.8 \%$ & $3 \%$ & $-4.2 \%$ & $0 \%$ & $1.9 \%$ & $0 \%$ & $11.0 \%$ \\
\hline Alcoholic beverages & $0 \%$ & $33.4 \%$ & $0 \%$ & $1.1 \%$ & $0 \%$ & $4.2 \%$ & $2 \%$ & $1.8 \%$ & $5 \%$ & $-3.1 \%$ & $0 \%$ & $0.3 \%$ & $0 \%$ & $-1.0 \%$ \\
\hline
\end{tabular}

* Except F\&V juices

Table A.1: Changes in food consumption induced by the imposition of dietary constraints (percentage on the right in each column) \& baseline contribution of each food group to the constrained quantity (percentage on the left in each column) for the "Modest" consumer type. 


\begin{tabular}{|c|c|c|c|c|c|c|c|c|c|c|c|c|c|c|}
\hline Upper average & \multicolumn{2}{|c|}{$\begin{array}{l}\mathrm{F} \& \mathrm{~V} \\
+5 \%\end{array}$} & \multicolumn{2}{|c|}{$\begin{array}{l}\mathrm{Na} \\
-5 \%\end{array}$} & \multicolumn{2}{|c|}{$\begin{array}{l}\text { SFA } \\
-5 \%\end{array}$} & \multicolumn{2}{|c|}{$\begin{array}{c}\text { Added sugar } \\
-5 \%\end{array}$} & \multicolumn{2}{|c|}{$\begin{array}{c}\text { eq. CO2 } \\
-5 \%\end{array}$} & \multicolumn{2}{|c|}{$\begin{array}{c}\text { Red meat } \\
-5 \%\end{array}$} & \multicolumn{2}{|c|}{$\begin{array}{c}\text { All meats } \\
-5 \%\end{array}$} \\
\hline Red meat & $0 \%$ & $-6.4 \%$ & $1 \%$ & $1.7 \%$ & $3 \%$ & $-0.9 \%$ & $0 \%$ & $6.8 \%$ & $14 \%$ & $-36.6 \%$ & $89 \%$ & $-5.5 \%$ & $23 \%$ & $-8.3 \%$ \\
\hline Other meats & $0 \%$ & $4.0 \%$ & $3 \%$ & $4.5 \%$ & $4 \%$ & $13.7 \%$ & $0 \%$ & $5.4 \%$ & $13 \%$ & $-8.9 \%$ & $0 \%$ & $0.7 \%$ & $39 \%$ & $-6.4 \%$ \\
\hline Cooked meats & $0 \%$ & $-2.4 \%$ & $19 \%$ & $-2.5 \%$ & $9 \%$ & $-4.3 \%$ & $0 \%$ & $-4.3 \%$ & $7 \%$ & $13.2 \%$ & $0 \%$ & $0.8 \%$ & $32 \%$ & $-1.1 \%$ \\
\hline All meats & $0 \%$ & $-0.4 \%$ & $23 \%$ & $1.7 \%$ & $16 \%$ & $4.7 \%$ & $1 \%$ & $2.7 \%$ & $34 \%$ & $-8.4 \%$ & $89 \%$ & $-0.7 \%$ & $93 \%$ & $-5.2 \%$ \\
\hline Milk products & $0 \%$ & $-3.2 \%$ & $6 \%$ & $3.0 \%$ & $8 \%$ & $-6.4 \%$ & $16 \%$ & $-0.1 \%$ & $12 \%$ & $-6.9 \%$ & $0 \%$ & $0.7 \%$ & $0 \%$ & $3.1 \%$ \\
\hline Cheeses, butters, fresh creams & $0 \%$ & $-2.2 \%$ & $15 \%$ & $-4.3 \%$ & $45 \%$ & $-7.2 \%$ & $0 \%$ & $-6.6 \%$ & $10 \%$ & $5.1 \%$ & $0 \%$ & $0.1 \%$ & $0 \%$ & $4.0 \%$ \\
\hline Dairy pdts & $0 \%$ & $-3.0 \%$ & $21 \%$ & $1.5 \%$ & $53 \%$ & $-6.6 \%$ & $16 \%$ & $-1.4 \%$ & $22 \%$ & $-4.5 \%$ & $0 \%$ & $0.6 \%$ & $0 \%$ & $3.3 \%$ \\
\hline Fish & $0 \%$ & $4.6 \%$ & $4 \%$ & $6.7 \%$ & $1 \%$ & $8.1 \%$ & $0 \%$ & $4.5 \%$ & $4 \%$ & $27.8 \%$ & $0 \%$ & $1.5 \%$ & $0 \%$ & $6.8 \%$ \\
\hline Eggs & $0 \%$ & $-5.4 \%$ & $1 \%$ & $4.8 \%$ & $2 \%$ & $-16.4 \%$ & $0 \%$ & $-2.4 \%$ & $2 \%$ & $-16.6 \%$ & $0 \%$ & $-0.9 \%$ & $0 \%$ & $-3.5 \%$ \\
\hline Animal pdts & $0 \%$ & $-1.8 \%$ & $29 \%$ & $2.0 \%$ & $19 \%$ & $-2.8 \%$ & $1 \%$ & $0.1 \%$ & $40 \%$ & $-3.6 \%$ & $89 \%$ & $0.2 \%$ & $93 \%$ & $1.0 \%$ \\
\hline Grains & $0 \%$ & $-4.6 \%$ & $13 \%$ & $-16.9 \%$ & $1 \%$ & $-3.5 \%$ & $1 \%$ & $-1.2 \%$ & $2 \%$ & $-7.7 \%$ & $0 \%$ & $-1.1 \%$ & $0 \%$ & $-0.7 \%$ \\
\hline Potatoes & $0 \%$ & $-19.5 \%$ & $1 \%$ & $-3.0 \%$ & $2 \%$ & $2.4 \%$ & $0 \%$ & $-2.7 \%$ & $1 \%$ & $-18.7 \%$ & $0 \%$ & $-0.8 \%$ & $0 \%$ & $-4.7 \%$ \\
\hline Starchy food & $0 \%$ & $-12.2 \%$ & $14 \%$ & $-9.8 \%$ & $2 \%$ & $-0.5 \%$ & $1 \%$ & $-2.0 \%$ & $3 \%$ & $-13.3 \%$ & $0 \%$ & $-1.0 \%$ & $0 \%$ & $-2.7 \%$ \\
\hline Fruits - Fresh & $42 \%$ & $2.1 \%$ & $0 \%$ & $0.3 \%$ & $0 \%$ & $-3.7 \%$ & $0 \%$ & $0.9 \%$ & $4 \%$ & $15.6 \%$ & $0 \%$ & $1.3 \%$ & $0 \%$ & $2.5 \%$ \\
\hline Fruits - Processed & $2 \%$ & $17.4 \%$ & $0 \%$ & $1.9 \%$ & $0 \%$ & $-33.0 \%$ & $4 \%$ & $-5.1 \%$ & $0 \%$ & $20.0 \%$ & $0 \%$ & $0.1 \%$ & $0 \%$ & $-3.7 \%$ \\
\hline F\&V juices & $5 \%$ & $2.5 \%$ & $0 \%$ & $3.6 \%$ & $0 \%$ & $3.9 \%$ & $3 \%$ & $15.0 \%$ & $2 \%$ & $-1.2 \%$ & $0 \%$ & $0.8 \%$ & $0 \%$ & $-0.5 \%$ \\
\hline Vegetables - Fresh & $36 \%$ & $8.3 \%$ & $4 \%$ & $5.7 \%$ & $0 \%$ & $14.0 \%$ & $0 \%$ & $-1.5 \%$ & $5 \%$ & $1.7 \%$ & $0 \%$ & $-0.4 \%$ & $0 \%$ & $0.0 \%$ \\
\hline Vegetables - Processed & $8 \%$ & $11.8 \%$ & $4 \%$ & $-2.9 \%$ & $0 \%$ & $10.2 \%$ & $0 \%$ & $5.7 \%$ & $2 \%$ & $-10.9 \%$ & $0 \%$ & $-0.1 \%$ & $0 \%$ & $-3.4 \%$ \\
\hline Fruits - Dry & $0 \%$ & $-3.4 \%$ & $0 \%$ & $10.2 \%$ & $0 \%$ & $-3.8 \%$ & $0 \%$ & $-16.9 \%$ & $0 \%$ & $48.4 \%$ & $0 \%$ & $1.2 \%$ & $0 \%$ & $9.8 \%$ \\
\hline $\mathrm{F} \& \mathrm{~V} *$ & $94 \%$ & $5.7 \%$ & $9 \%$ & $2.3 \%$ & $1 \%$ & $3.9 \%$ & $7 \%$ & $0.1 \%$ & $13 \%$ & $8.2 \%$ & $0 \%$ & $0.5 \%$ & $0 \%$ & $0.9 \%$ \\
\hline Ready meals & $4 \%$ & $-8.1 \%$ & $9 \%$ & $-7.9 \%$ & $4 \%$ & $-6.4 \%$ & $1 \%$ & $-6.3 \%$ & $6 \%$ & $-13.8 \%$ & $10 \%$ & $-1.1 \%$ & $6 \%$ & $-3.8 \%$ \\
\hline Oil, margarine, condiments & $0 \%$ & $8.4 \%$ & $4 \%$ & $6.0 \%$ & $9 \%$ & $-0.4 \%$ & $0 \%$ & $4.2 \%$ & $1 \%$ & $-1.6 \%$ & $0 \%$ & $0.1 \%$ & $0 \%$ & $-1.6 \%$ \\
\hline Salt-fat products & $0 \%$ & $-15.0 \%$ & $7 \%$ & $-28.1 \%$ & $1 \%$ & $-29.4 \%$ & $0 \%$ & $7.9 \%$ & $1 \%$ & $18.8 \%$ & $0 \%$ & $1.2 \%$ & $0 \%$ & $10.4 \%$ \\
\hline Sugar-fat products & $2 \%$ & $1.5 \%$ & $5 \%$ & $-1.2 \%$ & $11 \%$ & $-6.6 \%$ & $57 \%$ & $-3.8 \%$ & $5 \%$ & $0.9 \%$ & $0 \%$ & $0.1 \%$ & $0 \%$ & $-0.1 \%$ \\
\hline Soft drinks & $0 \%$ & $-14.7 \%$ & $0 \%$ & $-8.0 \%$ & $0 \%$ & $0.8 \%$ & $13 \%$ & $-22.7 \%$ & $1 \%$ & $32.1 \%$ & $0 \%$ & $0.8 \%$ & $0 \%$ & $5.6 \%$ \\
\hline Water & $0 \%$ & $-13.6 \%$ & $1 \%$ & $1.5 \%$ & $0 \%$ & $9.1 \%$ & $0 \%$ & $7.9 \%$ & $3 \%$ & $-5.5 \%$ & $0 \%$ & $1.7 \%$ & $0 \%$ & $9.4 \%$ \\
\hline Alcoholic beverages & $0 \%$ & $6.5 \%$ & $0 \%$ & $1.4 \%$ & $0 \%$ & $4.9 \%$ & $3 \%$ & $2.1 \%$ & $6 \%$ & $0.0 \%$ & $0 \%$ & $0.3 \%$ & $0 \%$ & $-0.2 \%$ \\
\hline
\end{tabular}

Table A.2: Changes in food consumption induced by the imposition of dietary constraints (percentage on the right in each column) \& baseline contribution of each food group to the constrained quantity (percentage on the left in each column) for the "Upper-average" consumer type.

\begin{tabular}{|c|c|c|c|c|c|c|c|c|c|c|c|c|c|c|}
\hline Well-off & \multicolumn{2}{|c|}{$\begin{array}{l}\mathrm{F} \& \mathrm{~V} \\
+5 \%\end{array}$} & \multicolumn{2}{|c|}{$\begin{array}{l}\mathrm{Na} \\
-5 \%\end{array}$} & \multicolumn{2}{|c|}{$\begin{array}{l}\text { SFA } \\
-5 \%\end{array}$} & \multicolumn{2}{|c|}{$\begin{array}{c}\text { Added sugar } \\
-5 \%\end{array}$} & \multicolumn{2}{|c|}{$\begin{array}{c}\text { eq. CO2 } \\
-5 \%\end{array}$} & \multicolumn{2}{|c|}{$\begin{array}{c}\text { Red meat } \\
-5 \%\end{array}$} & \multicolumn{2}{|c|}{$\begin{array}{c}\text { All meats } \\
-5 \%\end{array}$} \\
\hline Red meat & $0 \%$ & $-5.4 \%$ & $2 \%$ & $1.5 \%$ & $4 \%$ & $-1.5 \%$ & $0 \%$ & $12.2 \%$ & $14 \%$ & $-36.6 \%$ & $89 \%$ & $-5.5 \%$ & $24 \%$ & $-8.7 \%$ \\
\hline Other meats & $0 \%$ & $3.5 \%$ & $3 \%$ & $4.5 \%$ & $4 \%$ & $14.2 \%$ & $0 \%$ & $8.7 \%$ & $12 \%$ & $-8.6 \%$ & $0 \%$ & $0.7 \%$ & $38 \%$ & $-6.4 \%$ \\
\hline Cooked meats & $0 \%$ & $-1.9 \%$ & $18 \%$ & $-2.5 \%$ & $8 \%$ & $-5.1 \%$ & $0 \%$ & $-10.2 \%$ & $7 \%$ & $13.4 \%$ & $0 \%$ & $0.9 \%$ & $30 \%$ & $-0.6 \%$ \\
\hline All meats & $0 \%$ & $-0.3 \%$ & $22 \%$ & $1.7 \%$ & $16 \%$ & $4.5 \%$ & $1 \%$ & $3.8 \%$ & $33 \%$ & $-8.8 \%$ & $89 \%$ & $-0.7 \%$ & $93 \%$ & $-5.2 \%$ \\
\hline Milk products & $0 \%$ & $-2.6 \%$ & $6 \%$ & $3.0 \%$ & $8 \%$ & $-7.3 \%$ & $16 \%$ & $-1.9 \%$ & $11 \%$ & $-6.6 \%$ & $0 \%$ & $0.7 \%$ & $0 \%$ & $3.1 \%$ \\
\hline Cheeses, butters, fresh creams & $0 \%$ & $-2.0 \%$ & $16 \%$ & $-4.4 \%$ & $46 \%$ & $-7.4 \%$ & $0 \%$ & $-12.8 \%$ & $10 \%$ & $4.7 \%$ & $0 \%$ & $0.1 \%$ & $0 \%$ & $4.0 \%$ \\
\hline Dairy pdts & $0 \%$ & $-2.5 \%$ & $22 \%$ & $1.4 \%$ & $54 \%$ & $-7.3 \%$ & $16 \%$ & $-4.3 \%$ & $21 \%$ & $-4.1 \%$ & $0 \%$ & $0.6 \%$ & $0 \%$ & $3.3 \%$ \\
\hline Fish & $0 \%$ & $2.4 \%$ & $5 \%$ & $5.9 \%$ & $1 \%$ & $7.6 \%$ & $0 \%$ & $7.6 \%$ & $5 \%$ & $24.5 \%$ & $0 \%$ & $1.3 \%$ & $0 \%$ & $6.3 \%$ \\
\hline Eggs & $0 \%$ & $-4.5 \%$ & $1 \%$ & $5.0 \%$ & $2 \%$ & $-17.3 \%$ & $0 \%$ & $-6.6 \%$ & $2 \%$ & $-16.7 \%$ & $0 \%$ & $-0.9 \%$ & $0 \%$ & $-4.1 \%$ \\
\hline Animal pdts & $0 \%$ & $-1.6 \%$ & $29 \%$ & $2.0 \%$ & $19 \%$ & $-3.2 \%$ & $1 \%$ & $-1.2 \%$ & $39 \%$ & $-3.4 \%$ & $89 \%$ & $0.2 \%$ & $93 \%$ & $1.0 \%$ \\
\hline Grains & $0 \%$ & $-3.9 \%$ & $12 \%$ & $-17.0 \%$ & $1 \%$ & $-4.6 \%$ & $1 \%$ & $-3.3 \%$ & $2 \%$ & $-8.4 \%$ & $0 \%$ & $-1.2 \%$ & $0 \%$ & $-1.1 \%$ \\
\hline Potatoes & $0 \%$ & $-17.0 \%$ & $1 \%$ & $-3.3 \%$ & $1 \%$ & $3.2 \%$ & $0 \%$ & $-6.3 \%$ & $1 \%$ & $-19.4 \%$ & $0 \%$ & $-0.9 \%$ & $0 \%$ & $-5.7 \%$ \\
\hline Starchy food & $0 \%$ & $-10.2 \%$ & $13 \%$ & $-10.3 \%$ & $2 \%$ & $-0.8 \%$ & $1 \%$ & $-4.8 \%$ & $3 \%$ & $-13.7 \%$ & $0 \%$ & $-1.1 \%$ & $0 \%$ & $-3.3 \%$ \\
\hline Fruits - Fresh & $46 \%$ & $4.1 \%$ & $0 \%$ & $0.7 \%$ & $0 \%$ & $-2.3 \%$ & $0 \%$ & $1.4 \%$ & $4 \%$ & $14.2 \%$ & $0 \%$ & $1.1 \%$ & $0 \%$ & $2.5 \%$ \\
\hline Fruits - Processed & $2 \%$ & $13.2 \%$ & $0 \%$ & $1.7 \%$ & $0 \%$ & $-34.5 \%$ & $4 \%$ & $-6.6 \%$ & $0 \%$ & $19.6 \%$ & $0 \%$ & $0.2 \%$ & $0 \%$ & $-4.2 \%$ \\
\hline F\&V juices & $5 \%$ & $1.9 \%$ & $0 \%$ & $3.5 \%$ & $0 \%$ & $3.4 \%$ & $3 \%$ & $26.1 \%$ & $2 \%$ & $-1.6 \%$ & $0 \%$ & $0.8 \%$ & $0 \%$ & $-0.6 \%$ \\
\hline Vegetables - Fresh & $35 \%$ & $7.1 \%$ & $5 \%$ & $5.1 \%$ & $1 \%$ & $13.1 \%$ & $0 \%$ & $-2.9 \%$ & $5 \%$ & $1.4 \%$ & $0 \%$ & $-0.3 \%$ & $0 \%$ & $0.0 \%$ \\
\hline Vegetables - Processed & $6 \%$ & $8.7 \%$ & $4 \%$ & $-2.5 \%$ & $0 \%$ & $10.0 \%$ & $0 \%$ & $10.1 \%$ & $2 \%$ & $-11.9 \%$ & $0 \%$ & $-0.1 \%$ & $0 \%$ & $-4.6 \%$ \\
\hline Fruits - Dry & $1 \%$ & $-2.3 \%$ & $0 \%$ & $8.5 \%$ & $0 \%$ & $-3.1 \%$ & $0 \%$ & $-23.6 \%$ & $0 \%$ & $41.8 \%$ & $0 \%$ & $1.0 \%$ & $0 \%$ & $8.5 \%$ \\
\hline $\mathrm{F \& V} *$ & $94 \%$ & $5.7 \%$ & $9 \%$ & $2.2 \%$ & $1 \%$ & $3.8 \%$ & $8 \%$ & $0.0 \%$ & $13 \%$ & $7.8 \%$ & $0 \%$ & $0.5 \%$ & $0 \%$ & $1.0 \%$ \\
\hline Ready meals & $4 \%$ & $-6.2 \%$ & $11 \%$ & $-7.7 \%$ & $4 \%$ & $-6.4 \%$ & $1 \%$ & $-11.2 \%$ & $6 \%$ & $-13.3 \%$ & $11 \%$ & $-1.1 \%$ & $7 \%$ & $-3.9 \%$ \\
\hline Oil, margarine, condiments & $0 \%$ & $7.4 \%$ & $4 \%$ & $7.4 \%$ & $8 \%$ & $3.8 \%$ & $0 \%$ & $6.9 \%$ & $1 \%$ & $-2.4 \%$ & $0 \%$ & $0.0 \%$ & $0 \%$ & $-2.3 \%$ \\
\hline Salt-fat products & $0 \%$ & $-12.5 \%$ & $7 \%$ & $-28.3 \%$ & $1 \%$ & $-30.6 \%$ & $0 \%$ & $16.0 \%$ & $1 \%$ & $18.2 \%$ & $0 \%$ & $1.3 \%$ & $0 \%$ & $10.7 \%$ \\
\hline Sugar-fat products & $2 \%$ & $1.5 \%$ & $5 \%$ & $-1.6 \%$ & $10 \%$ & $-7.4 \%$ & $57 \%$ & $-3.1 \%$ & $4 \%$ & $-1.1 \%$ & $0 \%$ & $0.1 \%$ & $0 \%$ & $-0.6 \%$ \\
\hline Soft drinks & $0 \%$ & $-14.2 \%$ & $0 \%$ & $-11.0 \%$ & $0 \%$ & $-1.8 \%$ & $12 \%$ & $-29.3 \%$ & $1 \%$ & $37.7 \%$ & $0 \%$ & $0.9 \%$ & $0 \%$ & $6.5 \%$ \\
\hline Water & $0 \%$ & $-10.8 \%$ & $1 \%$ & $1.3 \%$ & $0 \%$ & $8.5 \%$ & $0 \%$ & $13.7 \%$ & $3 \%$ & $-6.0 \%$ & $0 \%$ & $1.6 \%$ & $0 \%$ & $9.2 \%$ \\
\hline Alcoholic beverages & $0 \%$ & $3.5 \%$ & $0 \%$ & $1.6 \%$ & $0 \%$ & $5.0 \%$ & $4 \%$ & $3.4 \%$ & $7 \%$ & $1.3 \%$ & $0 \%$ & $0.3 \%$ & $0 \%$ & $0.1 \%$ \\
\hline
\end{tabular}

*Except F\&V juices 
Table A.3: Changes in food consumption induced by the imposition of dietary constraints (percentage on the right in each column) \& baseline contribution of each food group to the constrained quantity (percentage on the left in each column) for the "Well-off" consumer type. 


\begin{tabular}{|c|c|c|}
\hline \multirow[b]{2}{*}{ Data / food groups } & \multicolumn{2}{|c|}{ LCA coefficients of food groups (Bertolucci et al. 2016) } \\
\hline & $\begin{array}{l}\text { Computed for the French } \\
\text { case * }\end{array}$ & $\begin{array}{l}\text { Based on the literature } \\
\text { review* }\end{array}$ \\
\hline Red meat & 1549 & 2607 \\
\hline Other meats & 852 & 653 \\
\hline Cooked meats & 606 & 815 \\
\hline All meats & 967 & 1247 \\
\hline Milk products & 163 & 196 \\
\hline Cheeses, butters, fresh creams & 536 & 863 \\
\hline Dairy pdts & 247 & 346 \\
\hline Fish & 591 & 358 \\
\hline Eggs & 367 & 473 \\
\hline Animal pdts & 504 & 633 \\
\hline Grains & 123 & 136 \\
\hline Potatoes & 99 & 42 \\
\hline Starchy food & 117 & 113 \\
\hline Fruits - Fresh & 90 & 148 \\
\hline Fruits - Processed & 120 & 161 \\
\hline F\&V juices & 91 & 161 \\
\hline Vegetables - Fresh & 128 & 182 \\
\hline Vegetables - Processed & 222 & 158 \\
\hline Fruits - Dry & 186 & 362 \\
\hline $\mathrm{F} \& \mathrm{~V}$ & 118 & 166 \\
\hline Ready meals & 427 & 435 \\
\hline Oil, margarine, condiments & 181 & 270 \\
\hline Salt-fat products & 150 & 257 \\
\hline Sugar-fat products & 244 & 244 \\
\hline Soft drinks & 52 & 36 \\
\hline Water (bottled, tap, hot drinks) & 19 & 21 \\
\hline Alcoholic beverages & 166 & 241 \\
\hline
\end{tabular}

Table A.4: LCA coefficients of food groups 